\title{
WestVirginiaUniversity
}

THE RESEARCH REPOSITORY @ WVU

Graduate Theses, Dissertations, and Problem Reports

2010

\section{Analyzing the role of CK2 and PP2A in Drosophila position effect variegation}

\author{
Swati Banerjee \\ West Virginia University
}

Follow this and additional works at: https://researchrepository.wvu.edu/etd

\section{Recommended Citation}

Banerjee, Swati, "Analyzing the role of CK2 and PP2A in Drosophila position effect variegation" (2010). Graduate Theses, Dissertations, and Problem Reports. 4563.

https://researchrepository.wvu.edu/etd/4563

This Thesis is protected by copyright and/or related rights. It has been brought to you by the The Research Repository @ WVU with permission from the rights-holder(s). You are free to use this Thesis in any way that is permitted by the copyright and related rights legislation that applies to your use. For other uses you must obtain permission from the rights-holder(s) directly, unless additional rights are indicated by a Creative Commons license in the record and/ or on the work itself. This Thesis has been accepted for inclusion in WVU Graduate Theses, Dissertations, and Problem Reports collection by an authorized administrator of The Research Repository @ WVU. For more information, please contact researchrepository@mail.wvu.edu. 


\title{
ANALYZING THE ROLE OF CK2 AND PP2A IN DROSOPHILA POSITION EFFECT VARIEGATION
}

\author{
Swati Banerjee
}

\author{
Thesis submitted to the \\ Eberly College of Arts and Sciences \\ at West Virginia University \\ In partial fulfillment of the requirements for the degree of
}

\section{Master of Science \\ In \\ Biology}

\author{
Dr. Clifton P. Bishop, Chair \\ Dr. Ashok P. Bidwai \\ Dr. Daniel Panaccione
}

Department of Biology

Morgantown, West Virginia 2010

Keyword: Drosophila; Position effect variegation (PEV); Chromatin Structure; Heterochromatin; CK2; PP2A; white (w); white-mottled $4\left(w^{m 4}\right)$; Stubble (Sb). 


\section{ABSTRACT \\ Analyzing The Role Of CK2 and PP2A In Drosophila Position Effect Variegation}

\section{Swati Banerjee}

The results of the investigation into the role of CK2 and PP2A in Drosophila position effect variegation (PEV) and chromatin modification are presented here. PEV is seen when a gene normally found in euchromatin is placed in close proximity to heterochromatin. The propensity of heterochromatin to spread down the chromosome often results in inactivation of the displaced gene by compaction into heterochromatin. The study presented here utilized two different PEV reporter genes for investigating the role of two posttranslational modifying enzymes, the kinase CK2 and the phosphatase PP2A in chromatin formation. The reporter genes used in this study encode for specific eye color and bristle phenotypes or morphology. The expression of these genes is affected when juxtaposed to heterochromatin, thus serving as a strong reporter to monitor the heterochromatic spread in PEV. Studies revealed that CK2 activity is required for either the establishment, maintenance, or perpetuation of euchromatin or, negatively controls the formation of heterochromatin. PP2A, on the other hand, acts in the opposite fashion - either by favoring the formation of heterochromatin or by inhibiting euchromatin. 
Table of Contents

\begin{tabular}{|l|l|}
\hline List of Contents & Page \\
\hline ABSTRACT & ii \\
\hline ACKNOWLEDGEMENT & iv \\
\hline LIST OF FIGURES: & v-vi \\
\hline LIST OF TABLES: & vi \\
\hline Article I - Introduction & 1 \\
\hline $\begin{array}{l}\text { Article II - Observing the effects of CK2 and PP2A on In(1)wm4 and T(2;3)SbV in } \\
\text { Drosophila position effect variegation (PEV) }\end{array}$ & 28 \\
\hline Article: III - Citations: & 68 \\
\hline Article: IV - Appendix & 73 \\
\hline
\end{tabular}




\section{ACKNOWLEDGEMENT}

I would like to thank my advisor Dr. Clifton P. Bishop for all his support and experienced vision. Without his constant moral support I would not be able to successfully work on my project. I would like to thank my committee members Dr. Ashok P. Bidwai and Dr. Daniel Panaccione for all their input and suggestions in every step in my project. I am grateful to the Radioactive Safety Department, Health Science, WVU, for giving me an opportunity to use the radiation machine for mutagenesis. I am thankful to Dr. Bischof, for providing me the pUAST-attB clone and BestGene Inc. for conducting the micro injection procedures. I would like to thank Dr. Karen S. Weiler for providing the fly stock $T(2 ; 3) S b V / T M 1, U b x$ and the Bloomington Stock Center for all the other fly stocks used in this study. Next, I am glad to have Regina, Stephanie, Tiffany, Beatriz and Ashley as my lab mates. They were very supportive, co-operative and friendly towards me, which made me feel home even away from it. I express my gratitude to the Department of Biology for all the facilities and funding provided throughout my graduate career. Pat, Wendy, Katrina, Dr Michelle Withers - all of them helped me to accomplish and flourish my teaching responsibilities in an enjoyable atmosphere. I am grateful to all the fellow graduate students for their moral support which again made me feel lucky enough to be a part of this scientific field.

Finally I would like to thank my parents and my brother for their love and support. Without their constant support it would be next to impossible for me to even being able to cope up with all the hurdles in my life so far. Lastly I would like to take a chance to mention gratefulness in word to my husband, Suman. Without his constant support, inspiration and co-operation and considerate sharing I would never be able to graduate. 


\section{LIST OF FIGURES:}

Figure 1 Structure of nucleosome 4

Figure 2 Illustration of chromatin structure 5

Figure 3 Typical locations of euchromatic and heterochromatic regions 6

Figure 4 Cytological position of the white gene in Drosophila___ 10

Figure 5 PEV of white gene in Drosophila___ 11

Figure 6 Effect of modifiers on $w^{\mathrm{m} 4} \ldots 13$

Figure 7 Human CK2 holoenzyme with the catalytic and regulatory subunit__ 18

Figure 8 The mutations in the CK2a-Tik allele__ 20

Figure 9 The mutations in the CK2 $\alpha-$ Tik $^{R}$ allele _ 22

Figure 10 Structure of PP2A tetramer __ 26

Figure 11 Effect of CK2-Tik on PEV. — 40

Figure 12 Effect of CK2MB on PEV _ 41

Figure 13 Effect of CK2-Tik ${ }^{R}$ on PEV __ 42

Figure 14 Red eye pigmentation assay result from the genetic cross between $w^{m 4}$;

Su(var)204/CyO and w/Y; Tik/TM3, Sb. 43

Figure 15 Red eye pigmentation assay result from the genetic cross between $w^{m 4}$;

Su(var)204/CyO and w/Y; CK2MB/TM3, Sb.

Figure 16 Red eye pigmentation assay result from the genetic cross between $w^{m 4}$;

Su(var)204/CyO and w/Y; Tik ${ }^{R} / T M 3$, Sb. 45

Figure 17 Combined red eye pigmentation assay result 46

Figure 18 Combined red eye pigmentation assay result from the blind studies 47

Figure 19 Effect of PP2A-mts on PEV. 49

Figure 20 Red eye pigmentation assay result from the genetic cross between $w^{m 4}$;

Su(var)204/CyO and w/Y; mts/Sco. 50

Figure 21 Effect of PP2A-mts on PEV. 52

Figure 22 Red eye pigmentation assay result from the genetic cross between $w^{m 4}$; Df(2L)E110/CyO and 53

Figure 23 Effect of Tik and Tik ${ }^{R}$ on different second chromosomal modifiers of PEV 57

Figure 24 Effect of Tik and Tik ${ }^{R}$ on different third chromosomal modifiers of PEV 58

Figure 25 Red eye pigmentation assay results from the crosses with second chromosomal PEV modifiers and CK2 alleles Tik and Tik ${ }^{R}$. 
Figure 26 Red eye pigmentation assay results from the crosses with third chromosomal PEV modifiers and CK2 alleles Tik and Tik ${ }^{R}$ 60

Figure 27 Effects of Tik and Tik ${ }^{R}$ on $T(2 ; 3) S b^{V}$ 65 Figure 28 Design of construct and landing sites 77 Figure 29 Cartoon of transgenic lines constructed in the study with the reporter genes locations with proximity to the heterochromatin before and after mutagenesis 79 


\section{LIST OF TABLES:}

Table 1 List of the modifiers of PEV:

Table 2 Effect of CK2 mutant alleles on Stubble variegation by showing average number of bristles 66

Table 3 The list of strains used in the study for constructing transgenic lines 


\section{Article I. \\ Introduction}


To a first approximation, all cells within an organism contain the exact same DNA sequences yet different cell types express different subsets of genes. How then is the correct subset selected for expression? The answer lies in the proteins that are associated with the DNA. Control over gene expression is exerted by the non-histone proteins associated with the genes. This association of proteins, RNA, and DNA is referred to as chromatin.

\section{Insights of Position Effect Variegation (PEV):}

\section{(a) Chromatin structure:}

In the eukaryotic genome, the basic unit of chromatin organization is the nucleosome, consisting of histone octamers (an $[\mathrm{H} 3+\mathrm{H} 4] 2$ tetramer and two dimers of $[\mathrm{H} 2 \mathrm{~A}+\mathrm{H} 2 \mathrm{~B}]$ ) wrapped with $\sim 167$ base pairs (bp) of two left-handed turned DNA. There is a $\sim 10-15$ bp of "Linker DNA" that extends to the next histone octamer (Tremethick, 2007). The histone octamer binds to the DNA through very stable interactions between the carboxy-terminal two-thirds of the core histones. The amino-terminal tails, on the other hand, are accessible to various chromosomal components.

\section{(b) Types of chromatin:}

Chromatin is mainly of two kinds - euchromatin and heterochromatin. Heterochromatin is differentiated from the latter one by the dense cytological appearance throughout the cell cycle and was first identified in insects and plant cells by Emil Heitz in 1920. This type of chromatin is generally inaccessible to the transcriptional machinery and thus is transcriptionally silent. On the other hand gene promoters located in euchromatin are more 
accessible and may be transcriptionally active. The two kinds of chromatin can easily be differentiated by examining nuclei, stained with DNA binding dyes under a light microscope. The deeply stained region is the heterochromatic region against the lightly stained or diffuse euchromatic background (Girton and Johansen, 2008). The lowcopy or single copy genes from which most of the cellular mRNAs are transcribed are located in the euchromatic region. Repetitive genes and DNA elements are located in the highly condensed heterochromatic region. With subsequent improvement of staining and technical developments of microscopes, heterochromatin was further subdivided into two types: "constitutive" and "facultative" heterochromatin.

Constitutive heterochromatin is commonly found around centromeres and telomeres with the same condensed appearance in all somatic cell types. Facultative heterochromatin on the other hand appears densely packaged with loss of gene expression. Further the scientists defined facultative heterochromatin as being transcriptionally silent as is the case for constitutive heterochromatin but with the potential to interconvert between heterochromatin and euchromatin (Girton and Johansen, 2008). 


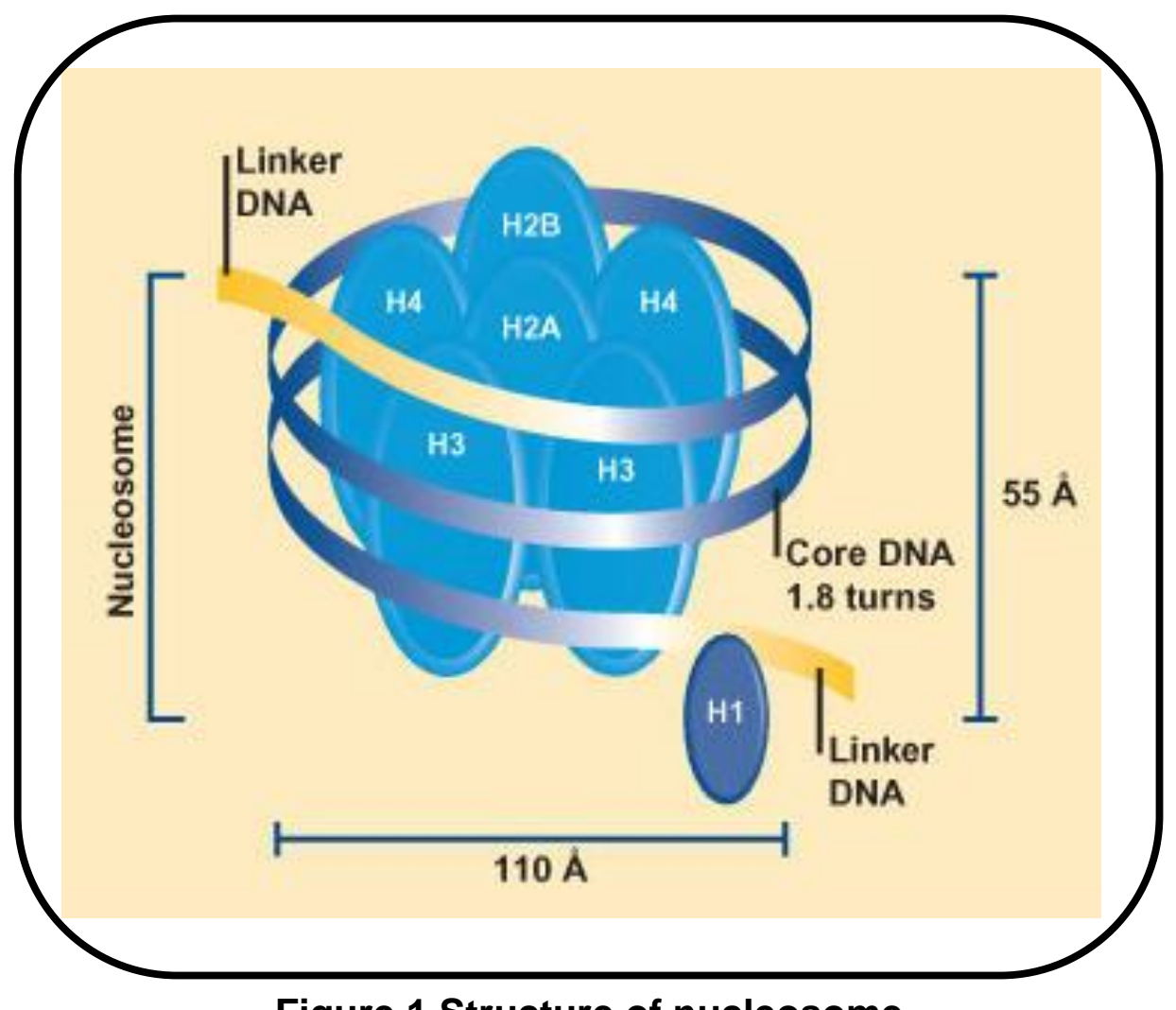

Figure 1 Structure of nucleosome

Approximately 146 base pairs of DNA are wound around a histone octamer consisting of two molecules each of $\mathrm{H} 2 \mathrm{~A}, \mathrm{H} 2 \mathrm{~B}$, $\mathrm{H} 3$, and $\mathrm{H} 4$ give rise to the nucleosome. The nucleosome is a dynamic structure that is regulated by numerous posttranslational modifications on both the $\mathrm{N}$ and $\mathrm{C}$-termini histone "tails". [Depicted from: (Downs et al., 2007)] 


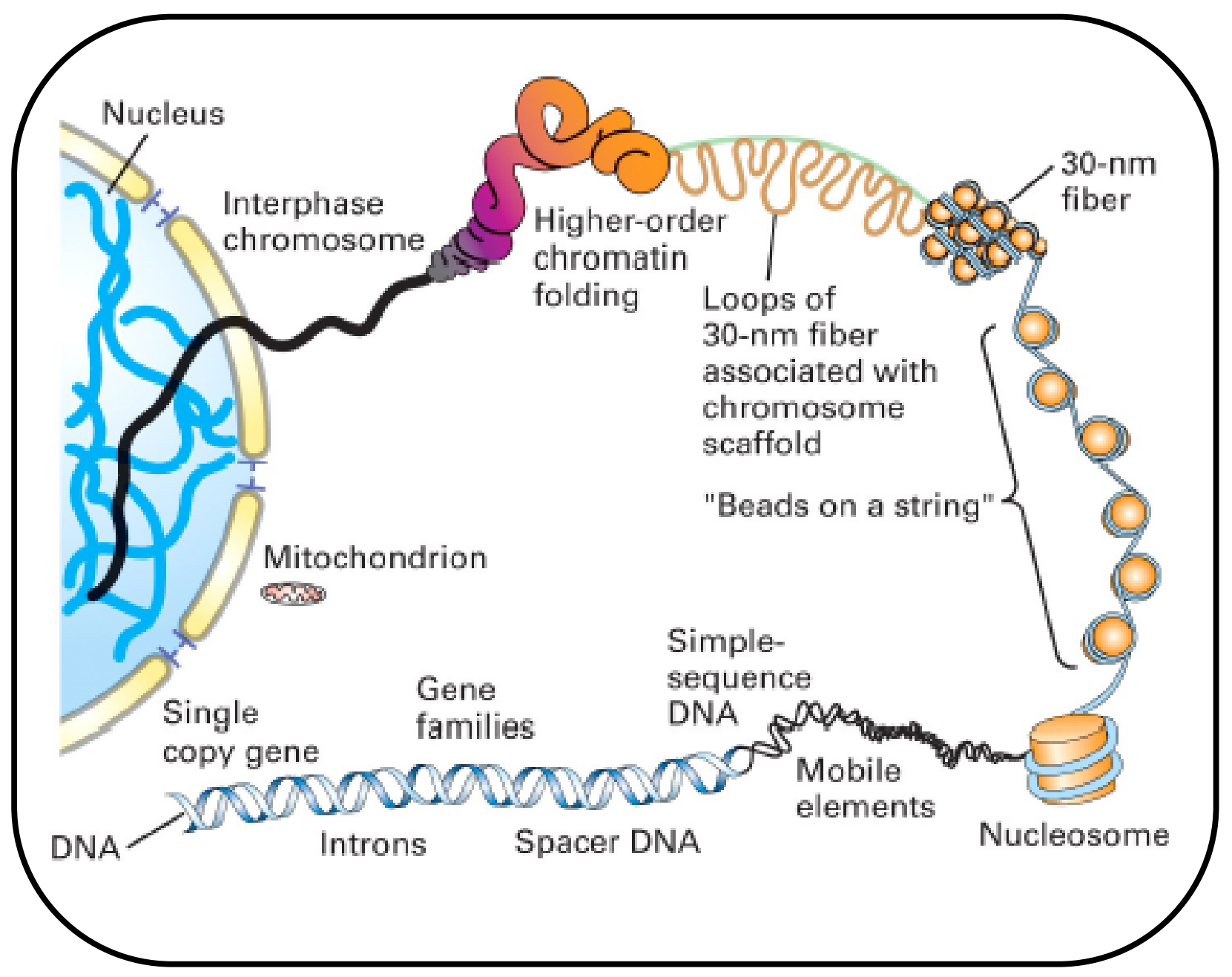

Figure 2 Illustration of chromatin structure

DNA gets condensed giving rise to the higher orders of chromatin structure.

[Depicted from: (Felsenfeld and Groudin, 2003)] 


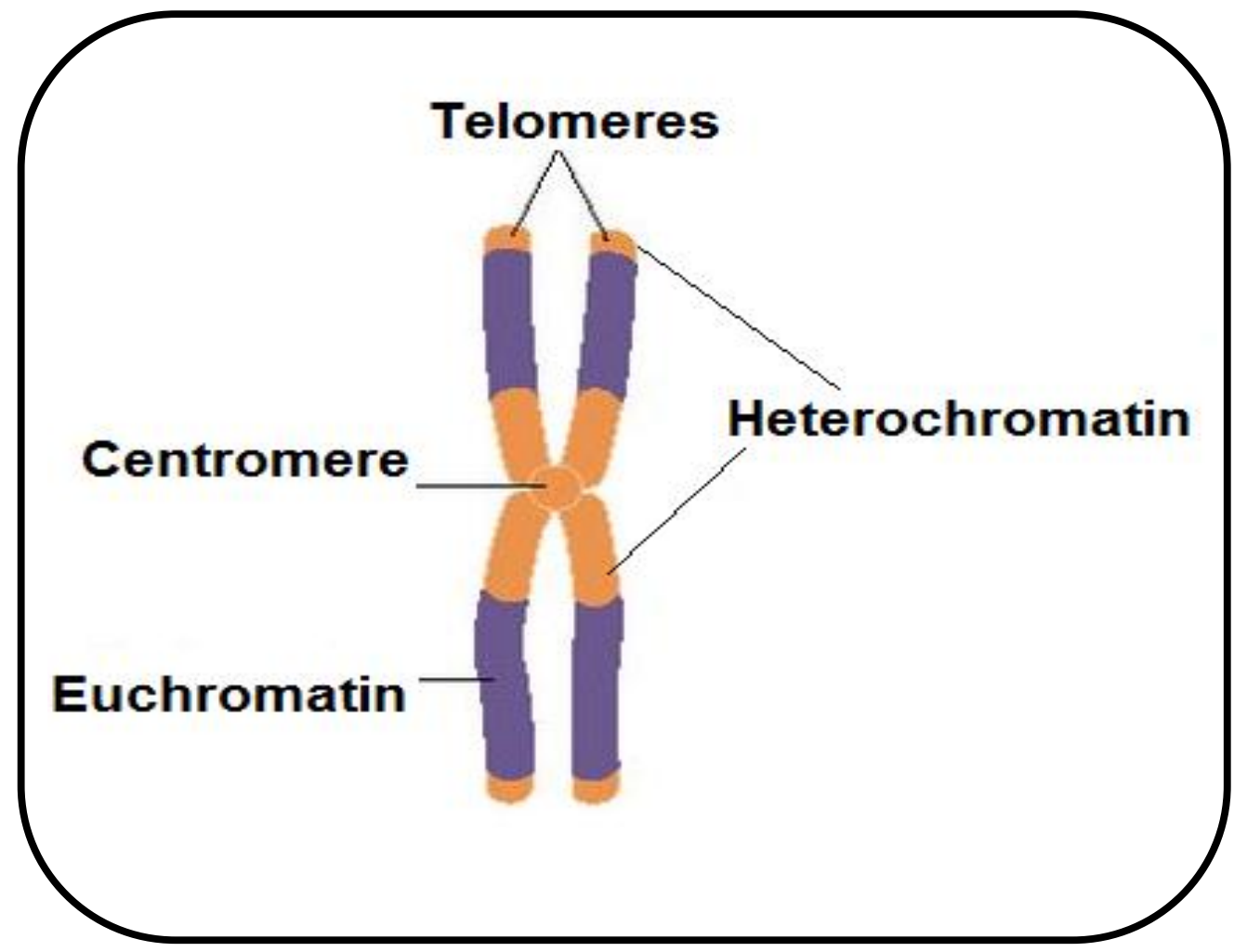

Figure 3 Typical locations of euchromatic and heterochromatic regions

Heterochromatic region is shown in 'orange' and the euchromatin is represented by blue color in the chromosome. [Depicted from:(Ussery, 1998)] 


\section{(c) Gene Silencing and PEV:}

The association of heterochromatin with gene silencing was first identified in Drosophila. In the phenomenon known as PEV, the euchromatic genes, when brought into the vicinity of the heterochromatic sequences, typically as the result chromosomal rearrangements, can be inactivated and show variegated phenotypes of those genes. This phenomenon was first described by Hans Muller (1930) in Drosophila. The inactivation of these transposed genes (Spofford, 1976) can result in a mosaic of non-expressing and expressing tissue. The genetic and molecular analysis of PEV in Drosophila provided immense support for gene silencing by heterochromatinization. According to Muller's examination, in all the thirteen observed mutants, the euchromatic genes had undergone a rearrangement (inversion, translocation) and their new location next to a constitutive heterochromatic block caused a variegated phenotype. The gene in the new location is inactivated in some cells but remained active in others, which caused patches of both the wild type as well as the mutant phenotype - producing the variegated phenotype (Henikoff, 1990). This inactivating effect of heterochromatin is extended for a limited distance from the heterochromatic breakpoint into the adjacent euchromatic regions and hence several genes may be affected. Today PEV phenomenon represents a valuable tool for the studies of epigenetic gene regulation and evolution of eukaryotic organisms (Surani et al., 2007; Turner, 2007).

\section{(d) Historical Background of PEV:}

As discussed earlier, Muller in 1930 described a number of Drosophila mutants that were obtained by X-ray irradiation. The first such mutation that Muller discovered was a dominant Notch wing mutation. He discovered that a fly heterozygous for the new Notch bearing chromosome and a chromosome containing a recessive mutation of the nearby 
white locus, had neither the solid white eye phenotype (with hypothesized deletion of both Notch and white) nor the solid red eye phenotype (with no such deletion) but mottled eyes with "various grades and sizes of lighter and darker areas" (Spofford, 1976). From his further studies and experiments he concluded that the change in chromosomal arrangement of the genes on the X-chromosome was responsible for such an appearance. Subsequent studies of several other genes demonstrated that specific types of chromosomal rearrangements with respect to the positioning of them in proximity to heterochromatin show these kinds of variegated phenotypes and thus the name "Position Effect variegation" was coined (Karpen, 1994).

\section{(e) Types of PEV:}

There are various ways in which mosaic phenotypes can be produced in Drosophila and these can be categorized into three classes or types (Girton and Johansen, 2008)

\section{(i) Chromosomal rearrangement PEV:}

This is caused either by moving an euchromatic gene into a pericentric heterochromatic region, or by moving a block of heterochromatic sequences into an euchromatic domain (Reuter and Spierer, 1992).

(ii) Transposon insertion PEV:

Transposons with euchromatic reporter genes when inserted into a heterochromatic block can also give rise to the PEV effect. This type of PEV was confirmed by various investigators (Ahmed and Golic, 1996; Girton and Johansen, 2008; Steller and Pirrotta, 1985; Wallrath and Elgin, 1995). 


\section{(iii) Pairing-dependent dominant PEV:}

Certain heterozygous flies having a rearranged brown $\left(b w^{D}\right)$ gene and wild-type brown gene $\left(b w^{+}\right)$have variegated brown eye color. This indicates the transassociation/inactivation effect (Sage and Csink, 2003).

\section{(f) PEV of white gene in Drosophila:}

In Drosophila, the white $(w)$ gene is the most widely used example of PEV. The wild type fly has a red coloration in its eye due to the proper euchromatic location and proper expression of this particular gene [Fig 5]. This gene is located on the euchromatic region of the X-chromosome. In the study presented here, an inversion of the white gene is used named white-mottled-4 $\left(w^{m 4}\right)$ which gives rise to "mottled" (scattered red pigments on white background) phenotype of the eye due to its proximity to heterochromatin (Tartof et al., 1989; Tartof et al., 1984), The euchromatic break point of this gene is located $\sim 25 \mathrm{~Kb}$ downstream from the white transcription start site (Tartof et al., 1984) [Fig-4]. PEV can also be due to a P-element insertion, which places a euchromatic gene into heterochromatic region (Talbert and Henikoff, 2000). More about this P-element induced PEV and its effects will be discussed later on in this thesis. 


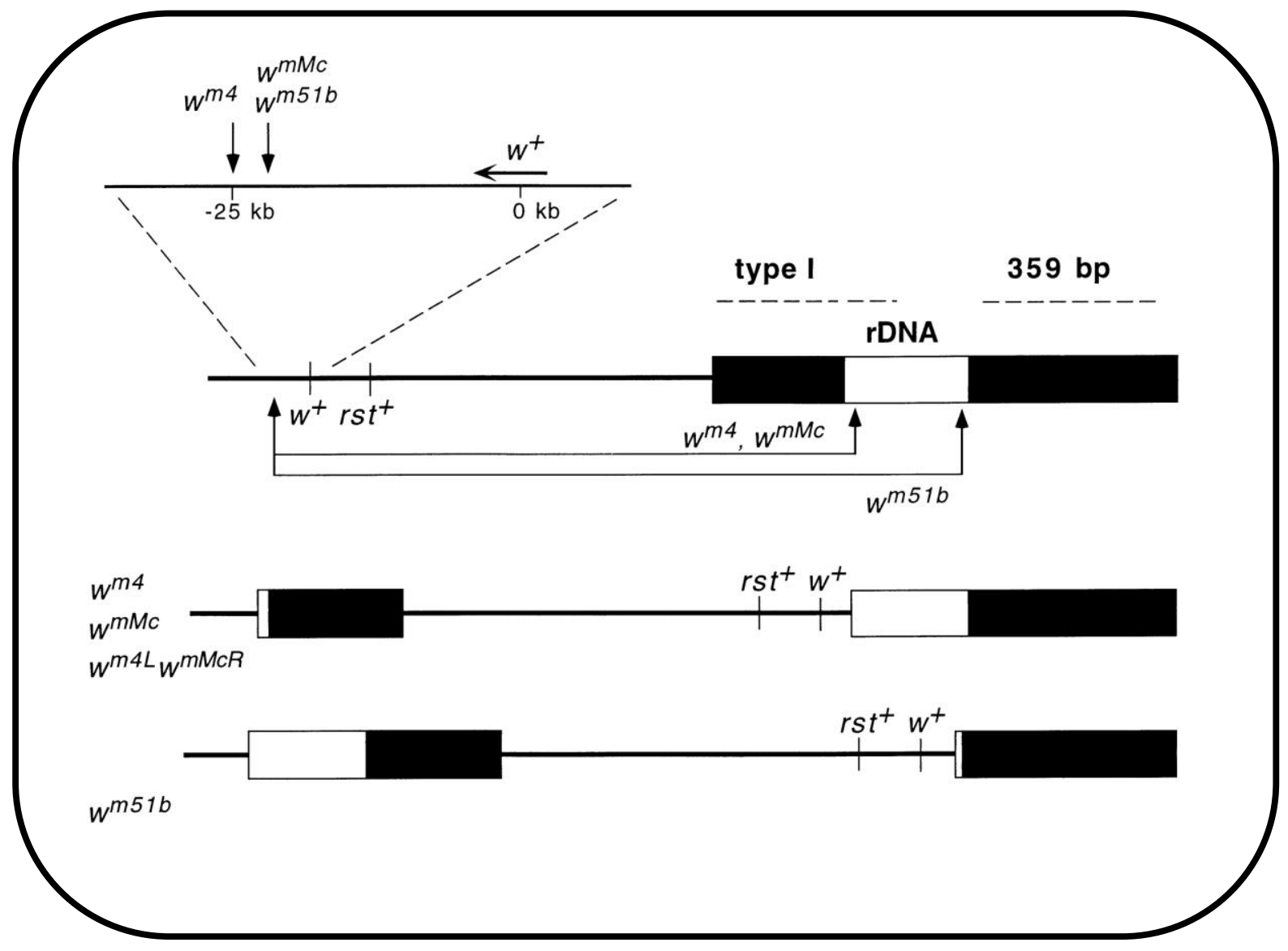

Figure 4 Cytological position of the white gene in Drosophila

Schematic diagrams of the $w^{m 4}, w^{m M c}$, and $w^{51 b}$ inversions. The top line is a magnified view of the region around the white gene. Other solid lines represent the $\mathrm{X}$ chromosome (not drawn to scale). Dashed lines indicate the location of type I and 359-bp repeats. Open boxes represent ribosomal DNA repeats; filled boxes are other heterochromatin; vertical and horizontal arrows are inversion breakpoints and the white transcription unit respectively [Depicted from: (Talbert and Henikoff, 2000) . 


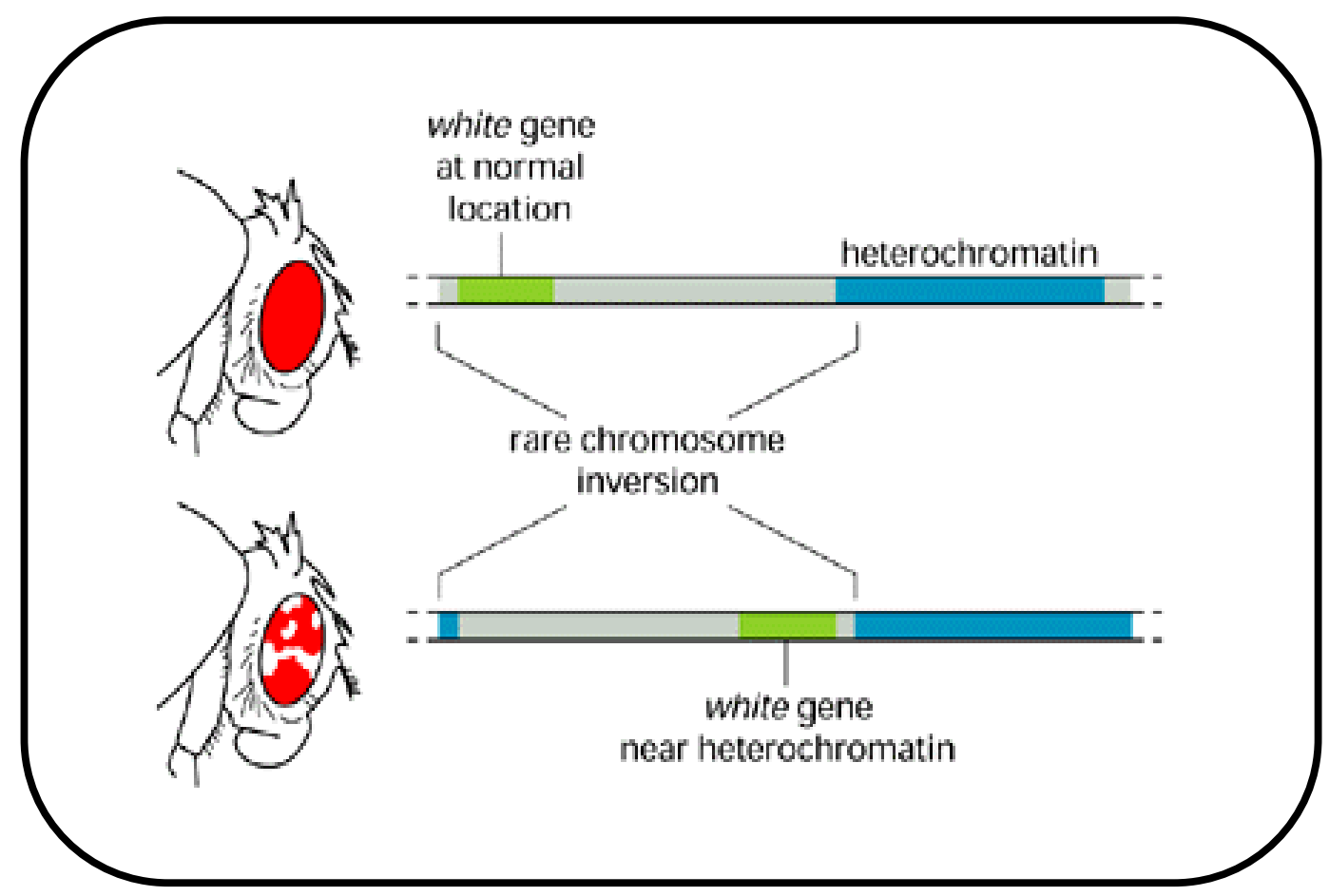

Figure 5 PEV of white gene in Drosophila

The white gene when located in its euchromatic location is expressed properly and gives red eye coloration as in the first picture. Due to a rare chromosomal inversion, when the white gene is placed closed to heterochromatic block, its expression is repressed, resulting in the mottling or variegated eye color as in the second picture. [Depicted from:(Sandell and Zakian, 1992)] 


\section{(g) PEV of Stubble gene in Drosophila:}

Another variegating reporter gene for PEV is known as Stubble-Variegating gene. In this case, the third chromosomal dominant Stubble mutation $(S b)$ is juxtaposed close to the second chromosome centric heterochromatin, due to a reciprocal translocation (Bishop, 1992; Hayashi et al., 1990; Weiler and Chatterjee, 2009). The Stubble gene in its normal euchromatic location is expressed properly and results in a shorter bristle phenotype. As a result of its translocation closer to heterochromatin, the PEV effect is exerted and the Stubble gene expression is repressed, giving rise to longer wild type bristle (Greil et al., 2007).

\section{(h) Modifiers of the PEV Phenotype:}

PEV can be strongly affected by certain modifiers that can increase (enhance variegation) or decrease (suppress variegation) the severity of the mutant or silencing phenotype [Fig 6]. Depending on the resulting variegation phenotypes, these modifiers can be divided into two categories: Suppressors of variegation or Su(var) and Enhancers of variegation or $E$ (var). A large number of dominant and recessive alleles of such modifiers have been recognized so far and there are an estimated 50-150 loci (Girton and Johansen, 2008) (Weiler and Wakimoto, 1995) that when mutated, show altered PEV phenotypes. Many of these modifier proteins have the putative phosphorylation site of a well-known kinase, CK2, present in them [Table 1] (Meggio and Pinna, 2003).

The CK2 consensus sequence S/DXXE/D is also evolutionarily conserved in most of the modifier proteins which motivates us to hypothesize that most of the modifiers act on chromatin modification or on PEV, after getting phosphorylated by CK2. The modifiers that have been used in this study are listed in Table 1. All of them are well known Su(var)s. 


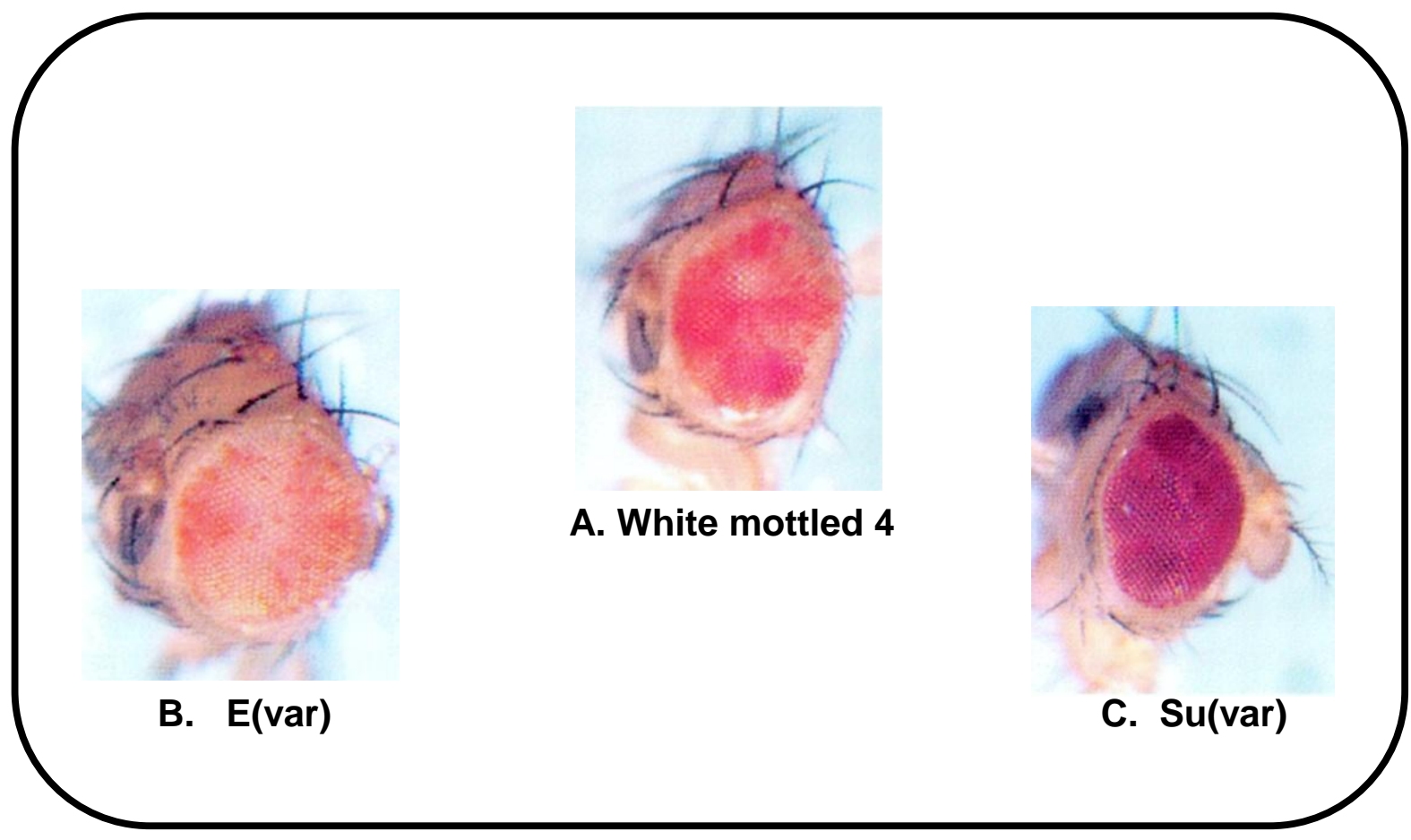

Figure 6 Effect of modifiers on $w^{m 4}$

A. The mottled eye in case of the $w^{m 4}$ inversion. B. Effects of Enhancer of variegations or $\mathrm{E}(\mathrm{var}) \mathrm{s}$ showing more silencing. $\mathbf{C}$. Effects of Suppressor of variegations or Su(var)s with lots of white gene expression. 
Table 1 List of the modifiers of PEV:

\begin{tabular}{|c|c|c|}
\hline Proteins & $\begin{array}{c}\text { Chromosomal } \\
\text { location }\end{array}$ & $\begin{array}{c}\text { Bloomington } \\
\text { Stock \# }\end{array}$ \\
\hline HP1 & Second & 6234 \\
\hline Lamin & Second & 25092 \\
\hline Piwi & Second & 12225 \\
\hline dCAPG & Second & 9456 \\
\hline Reptin & Third & 11706 \\
\hline Rpd3 & Third & 11633 \\
\hline Modulo & Third & 11795 \\
\hline ORC2 & Third & 9014 \\
\hline
\end{tabular}

Modifiers (with CK2 consensus sequences) that were used in the study with the respective stock numbers from the Bloomington Stock Center 
Because a number of modifiers of PEV contain the consensus sequence for phosphorylation by CK2 (Zhao and Eissenberg, 1999; Zhao et al., 2001a; Zhao et al., 2001b) three mutant alleles of CK2 were tested for their roles in PEV- in this project we will discuss the effects of CK2 on PEV by studying the CK2-allelic effects. Therefore we need to discuss the structural as well as functional aspects of CK2.

\section{Insights of CK2:}

\section{(a) Background study of CK2:}

Protein kinases act as central players in controlling nearly all cellular functions; particularly signal transduction pathways (Manning and Doe, 1999), gene expression, and protein synthesis (Allende and Allende, 1995). Unusually high activity of protein kinases often has pathological effects, namely neoplasia (Hunter and Cooper, 1986), which is a group of diseases commonly known as tumor or cancer. Nowadays, by developing efficient and selective cell-permeable inhibitors for each protein kinase, the functional roles and strategies of these enzymes can be determined (Battistutta et al., 2000). Also, by determining the crystal structures of the inhibitors bound to the protein kinases, it is possible to have an idea of important structural elements. Today there are about 300 crystal structures available that includes more than 40 protein kinases. Among those, CK2 has the largest number of known structures in a complex with its inhibitors (Moliner et al., 2003).

Protein kinase CK2 was formerly known as Casein Kinase 2 for its ability to phosphorylate an artificial casein substrate in vitro. CK2 is a serine/threonine protein kinase ubiquitously present in eukaryotic organisms (Pinna, 1990). This was also the first protein kinase to be discovered. 


\section{(b) Structural feature of CK2:}

\section{(i) THE CATALYTIC CK2 $\alpha$ SUBUNIT:}

CK2 holoenzyme is a tetramer composed of two catalytic subunits $(\alpha)$ and two regulatory subunits ( $\beta$ ) (Dotan et al., 2001). In many organisms, distinct forms of the catalytic subunit of CK2 have been identified (Bosc et al., 1995; Maridor et al., 1991; Messenger, 2002; Pawson and Nash, 2000; Tuazon, 1991). For example: in humans, there are two catalytic isoforms CK2 $\alpha$ and CK2 $\alpha^{\prime}$ with a third isoform CK2 $\alpha^{\prime \prime}$. Though there is only one regulatory subunit, CK2B, identified in humans, there are multiple forms of this subunit present in other organisms like Saccharomyces cerevisiae (S. cerevisiae) (Chantalat et al., 1999; Dotan et al., 2001). In mammals, the CK2 tetrameric complex can have identical (i.e. two CK2a or two CK2 $\alpha^{\prime}$ ) or non-identical (i.e. one CK2 $\alpha$ and one CK2 $\alpha^{\prime}$ ) catalytic subunits (Niefind et al., 1998). In Drosophila, however, there is only one gene encoding for CK2 $\alpha$.

(ii) THE REGULATORY B SUBUNIT:

The amino acid sequence of the regulatory $B$ subunit of $\mathrm{CK} 2$, is even more conserved among species than that of the CK2 $\alpha$ subunit (Graham and Litchfield, 2000). This subunit has an auto phosphorylation site consisting of Ser 2, Ser 3 and Ser 4 in its N-terminal portion, and another phosphorylation site at Ser 219 (Niefind et al., 2001). Its sequence resembles that of the destruction box conferring mitosis-specific degradation to cyclin B. This box might play a role in regulating the stability of the tetrameric CK2 or CK2 $B$ itself, in concert with other signals, like phosphorylation. There is a zinc-finger with four cysteine residues (Cys 109, Cys 114, Cys 137, Cys 140), which is responsible for mediating the dimerization of CK2ß (Kunttas-Tatli et al., 2009). A C-terminal region (residues 181-203) is 
also present that positively regulates the catalytic activity. The sequence of residues 55-64 (i.e. DLEPDEELED), is known as an auto-inhibitory region since it binds to polyamine that activates CK2 in vitro (Kunttas-Tatli et al., 2009). This sequence is also responsible for binding with the basic stretch of residues in the CK2 $\alpha$ subunit (i.e. residues 71-80) - hence helping in the tetramer formation (Kunttas-Tatli et al., 2009). 


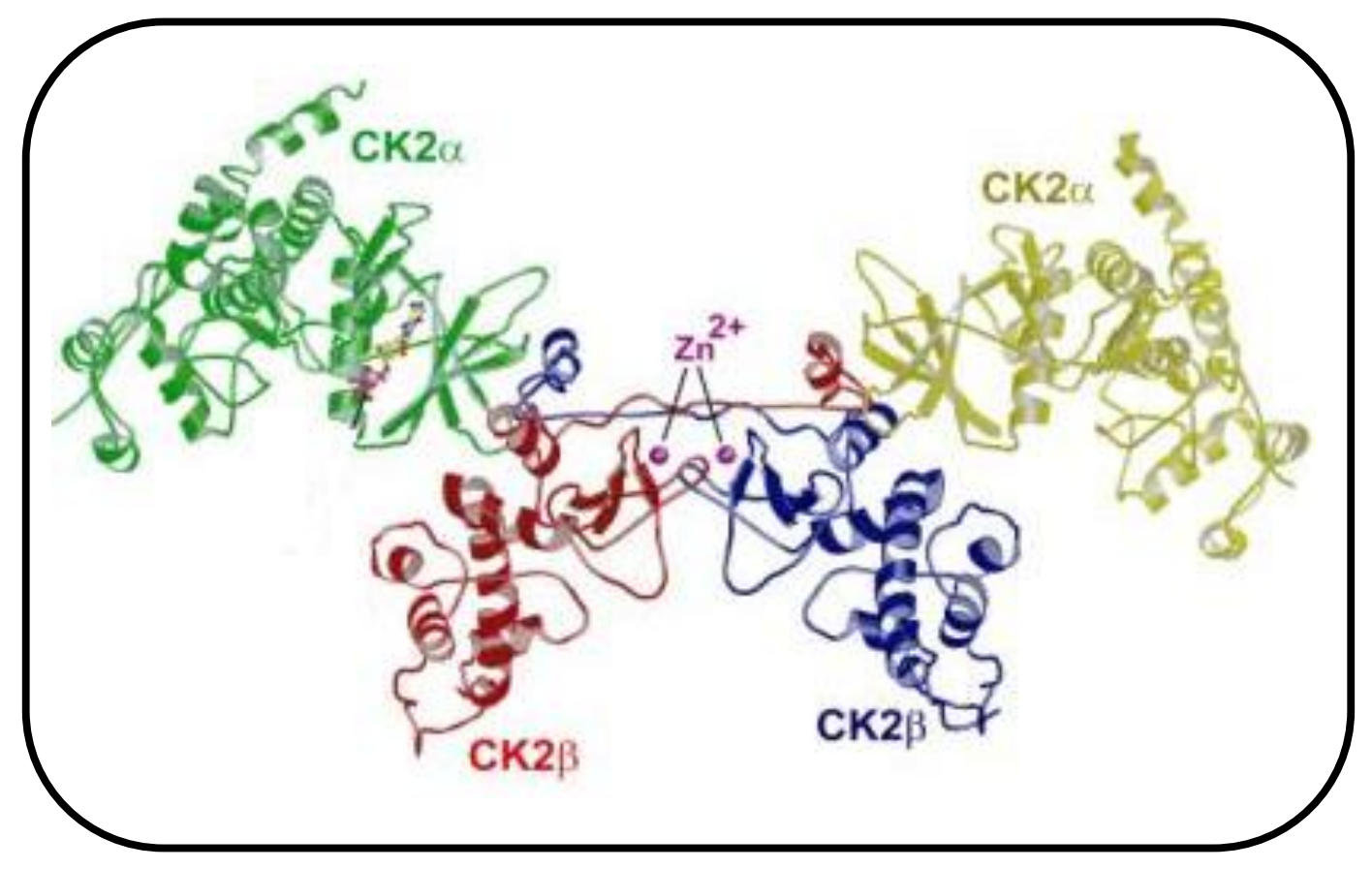

Figure 7 Human CK2 holoenzyme with the catalytic and regulatory subunit

The figure represents the human CK2 holoenzyme structure with the deep green and light green colored alpha subunits. Red and blue region represents the regulatory beta subunit.

[Model created by SwissProb software using the PDB file 1JHW from Protein Data Bank] 


\section{(c) ALLELES OF CK2:}

There are three CK2 $\alpha$ alleles - Timekeeper (Tik), Timekeeper Revertant $\left(\right.$ Tik $\left.^{R}\right)$ and $C K 2^{M B 0017}$. Both the Tik and Tik ${ }^{R}$ alleles were first identified as molecular clock proteins in D. melanogaster. In CK2a-Tik [Fig 8], there are two mutations. The Met161 is mutated to Lys $\left(M^{161} K\right)$ and Glu165 to Asp $\left(E^{165} \mathrm{D}\right)$ resulting in delayed circadian rhythm and loss of CK2 activity (Allada and Meissner, 2005). The amino acid Met161 is conserved throughout all the isoforms of CK2 $\alpha$. In humans the Met161 is located in the ATP binding pocket. Because of the substitution of Met, the non-charged residue, with the positively charged Lys residue, the ATP binding is impaired which impairs phosphorylation. Because of this, the bacterial expression of recombinant Tik construct showed reduced catalytic activity. Homozygous Tik larvae die as first instars. In contrast, the other mutation, Glu165 to Asp $\left(E^{165} \mathrm{D}\right)$ is believed not to have any direct effect on the catalytic activity of CK2. This is thought to be the case because of the fact that this Glu 165 residue is conserved throughout the metazoan group and its position in the hinge region can only interfere with the interaction with the $B$ subunit rather than affecting the catalytic activity (Kunttas-Tatli et al., 2009). It is thought, however, that this residue is critical for proper interactions with the phosphatase PP2A as discussed below. 


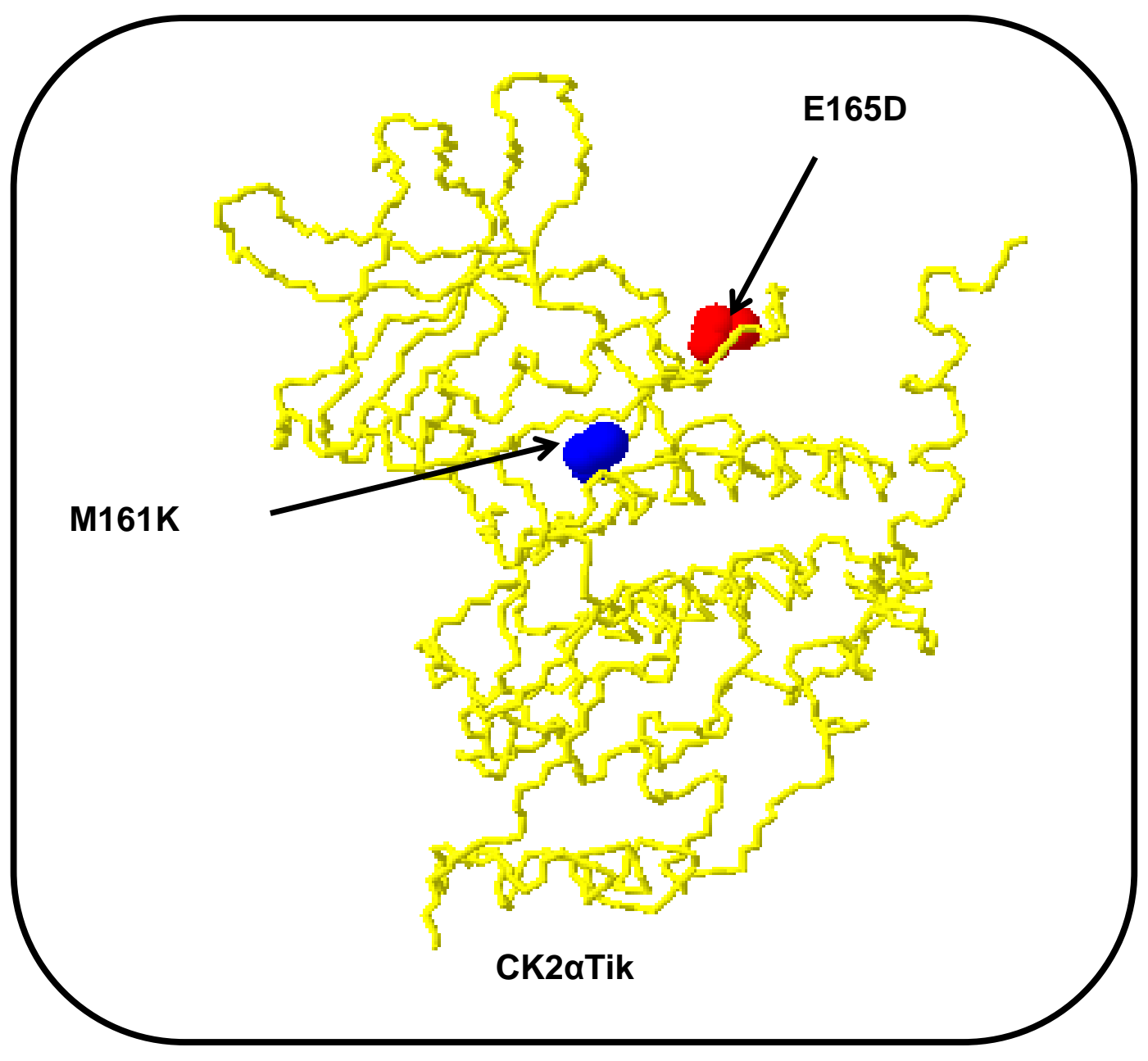

Figure 8 The mutations in the CK2a-Tik allele

The two substitutions that form the CK2 $\alpha$-Tik allele are shown with the arrows. The first mutation is M161K substitution (in blue) that alters the ATP binding site and the second one is the E165D substitution (in red) that confers the PP2A binding motif. 
Another CK2 allele, Tik ${ }^{R}$, not only contains the original two mutations as in Tik, but also contains an additional seven amino-acid deletion (234-240) and a substitution of Arg 242 to Glu (Lin et al., 2002) [Fig 9]. The amino acids that are mutated in $\mathrm{Tik}^{R}$ are also highly conserved. As far as the catalytic activity is concerned, the $T_{i k}^{R}$ lacks any catalytic activity and is homozygous lethal. It is believed that the internal deletion of the seven amino acids in $T i k^{R}$ results in protein misfolding which blocks $C K 2 \alpha-T i k^{R}$ from interacting with the endogenous CK2 2 subunit and thus hinders the holoenzyme formation. In case of Tik, however, CK2 $\alpha$ appears capable of complexing with the endogenous CK2ß and contributes to the holoenzyme formation. Thus CK2a-Tik can poison the holoenzyme and acts as a dominant-negative (DN) allele of CK2 by down regulating CK2 activity to less than $50 \%$. Tik was isolated as a circadian clock mutant, having a $\sim 48 \mathrm{hr}$ period whereas $\mathrm{Tik}^{R}$ reverts it back to 24 hrs (Lin et al., 2002) and appears to be a complete loss of function allele. These results are consistent with and support the notion that Tik is a DN allele.

Andante $(A n d)$ is the CK2ß allele so far isolated, which was also identified as a result of an altered circadian clock (Lin et al., 2002). This allele has a single amino acid substitution Met 161 to lle in the region of $\alpha / \beta$ interface, thus causing the loss of $\alpha / \beta$ interaction. However, there is some controversy regarding the proposed function of this particular allele in terms of human CK2B (Rasmussen et al., 2005). In this particular thesis we will only focus on the three $C K 2 \alpha$ alleles $-T i k, T_{i k}^{R}$ and $C K 2^{M B 0017}$ (henceforth referred to as CK2MB). 


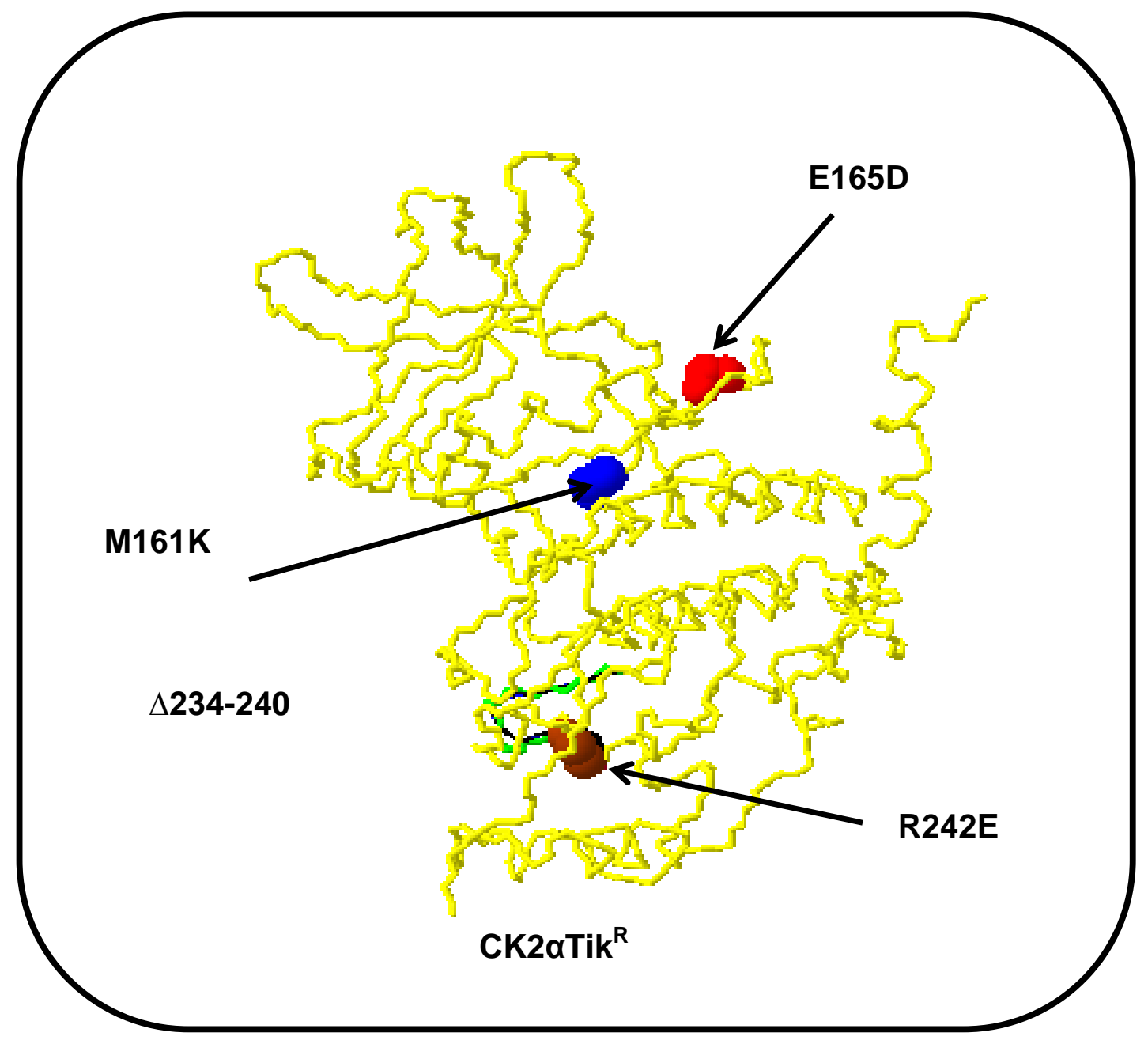

Figure 9 The mutations in the CK2a-Tik ${ }^{R}$ allele

Apart from the two original mutations as in Tik - M161K (in blue) and E165D (in red); Tik $^{R}$ has two additional mutations. The R242E is shown in brown and the seven amino acids that are deleted are shown in green. 


\section{(d) Significant roles of CK2:}

CK2 has various roles in numerous global processes, including neoplasia (Kelliher et al., 1996) and apoptosis. Additional roles of CK2 include cell signaling, gene expression and other nuclear processes (Guerra et al., 1999). Elevated level of CK2 have been observed in a wide range of tumors (Guerra et al., 1999; Tawfic and Ahmed, 1994). The relation between CK2 and neoplastic growth and the inclusion of many viral proteins among CK2 targets strongly suggests its role in viral pathologies as well. CK2 is one of the most conserved protein kinases in evolution, and the deletion of both of its catalytic subunits is lethal (Padmanabha et al., 1990). Also it plays a role in a number of global tasks (Bose et al., 2006; Dominguez et al., 2004; Ford et al., 2000; Keller et al., 2001; Sayed et al., 2000; Song et al., 2000; Torres and Pulido, 2001).

Amongst the substrates of CK2 is Protein Phosphatase 2A (PP2A) that can only associate with the CK2 $\alpha$ subunit but not with the holoenzyme (Meggio and Pinna, 2003). It has also been proven that CK2 and PP2A play antagonistic roles during the Notch signaling pathway (Kunttas-Tatli et al., 2009). In this thesis we are interested in roles of both CK2 and PP2A on chromatin modifications or PEV. Here we are also hypothesizing that there might be some antagonistic roles for the kinase and the phosphatase in chromatin modifications.

Previous studies by Kunttas-Tatli et. al., 2009, has revealed that PP2A interacts with CK2 $\alpha$ via its core dimer (catalytic $(C)$ and scaffolding subunit $(A)$ ) through a conserved sequence motif, HENRKL. In that particular study it was also shown that CK2 $\alpha$ could phosphorylate the PP2A catalytic subunit thus affecting the PP2A activity. Surprisingly, the $E^{165} D$ 
substitution in CK2 $\alpha$-Tik is a part of the HENRKL motif, which is crucial for the CK2 $\alpha$ PP2A interaction. Therefore it has been hypothesized that the $E^{165} \mathrm{D}$ mutation in Tik can interfere with the PP2A interaction and thus may alter PP2A activity (Kunttas-Tatli et al., 2009).

Therefore, while studying the effect of CK2 alleles on PEV, the effects of PP2A on the same PEV mutants, might produce some interesting results. This leads us to investigate the structural and functional aspects of PP2A.

\section{Insights on PP2A:}

PP2A is a well-known serine/threonine phosphatase that is involved in many essential aspects of cellular events (Janssens and Goris, 2001; Virshup and Shenolikar, 2009). The various physiological functions of PP2A include - cell cycle regulation, DNA replication, transcription, translation, cell growth control, development, regulation of signal transduction pathways, cytoskeleton dynamics and cell mobility (Xing et al., 2006).

\section{(a) Background study of PP2A:}

All known Ser/Thr protein phosphatases are encoded by two unrelated gene families namely PPM and PPP (Cohen et al., 1995). The PPM family is comprised of the $\mathrm{Mg}^{2+}$ dependent phosphatases which are structurally related to PP2C. On the other hand the PPP family has three subfamilies - PP1, PP2A and PP2B (calcineurin) (Moorhead et al., 2007). There is another novel divergent group of PPP phosphatases called PP5/rdgC subfamily. Several phylogenetic analyses suggest that the PP1/PP2A/PP2B subfamilies and the PP5/rdgC subfamilies represent two distinct branches of phosphatase evolution (Xing et al., 
2006). There are several specific structural features that also distinguish these two branches of PPP family. Apart from relatively low sequence identity between the two subfamilies, the PP1/PP2A/PP2B subfamilies share more conserved sequence similarities among the presumed orthologs from different species rather than that of the PP5/rdgC subfamily members (Xu et al., 2006). For example, the mammalian PP1 catalytic subunit is $76 \%-88 \%$ identical to those from plants and $90 \%$ identical to those from fungi (Bielinski and Mumby, 2007). On the other hand, the mammalian PP5 is only 65\% and $50 \%-58 \%$ identical to those from plants and fungi respectively. Among the members of the PP1/PP2A/PP2B subfamily, the sequence similarity is highly conserved except at the C-terminal residues between 274-277 (GEFD) of PP1, 267-270 (YRCG) of PP2A, and 312-316 (LDVYN) of PP2B (Lee et al., 2007). PP1 and PP2A show $41 \%$ amino acid sequence identity and these enzyme activities have been found abundantly in all eukaryotic cells examined to date (Mumby, 2007).

\section{(b) Structural feature of PP2A:}

PP2A is a trimeric holoenzyme comprised of the structural subunit A, regulatory subunit $B$, and catalytic subunit $\mathrm{C}$. The $36-\mathrm{kD}$ catalytic subunit $\mathrm{C}$ is bound to the $65 \mathrm{kD}$ regulatory subunit A, also known as PR65 and one of the regulatory subunits $B$ which range in size from 54-74 kD (Wassarman et al., 1996). The association of the core enzyme to various regulatory subunits can form several versions of the trimeric holoenzyme and is also responsible for enzyme activity (Vereshchagina et al., 2008), substrate specificity (Junttila et al., 2008), and sub-cellular localization of the holoenzyme. 


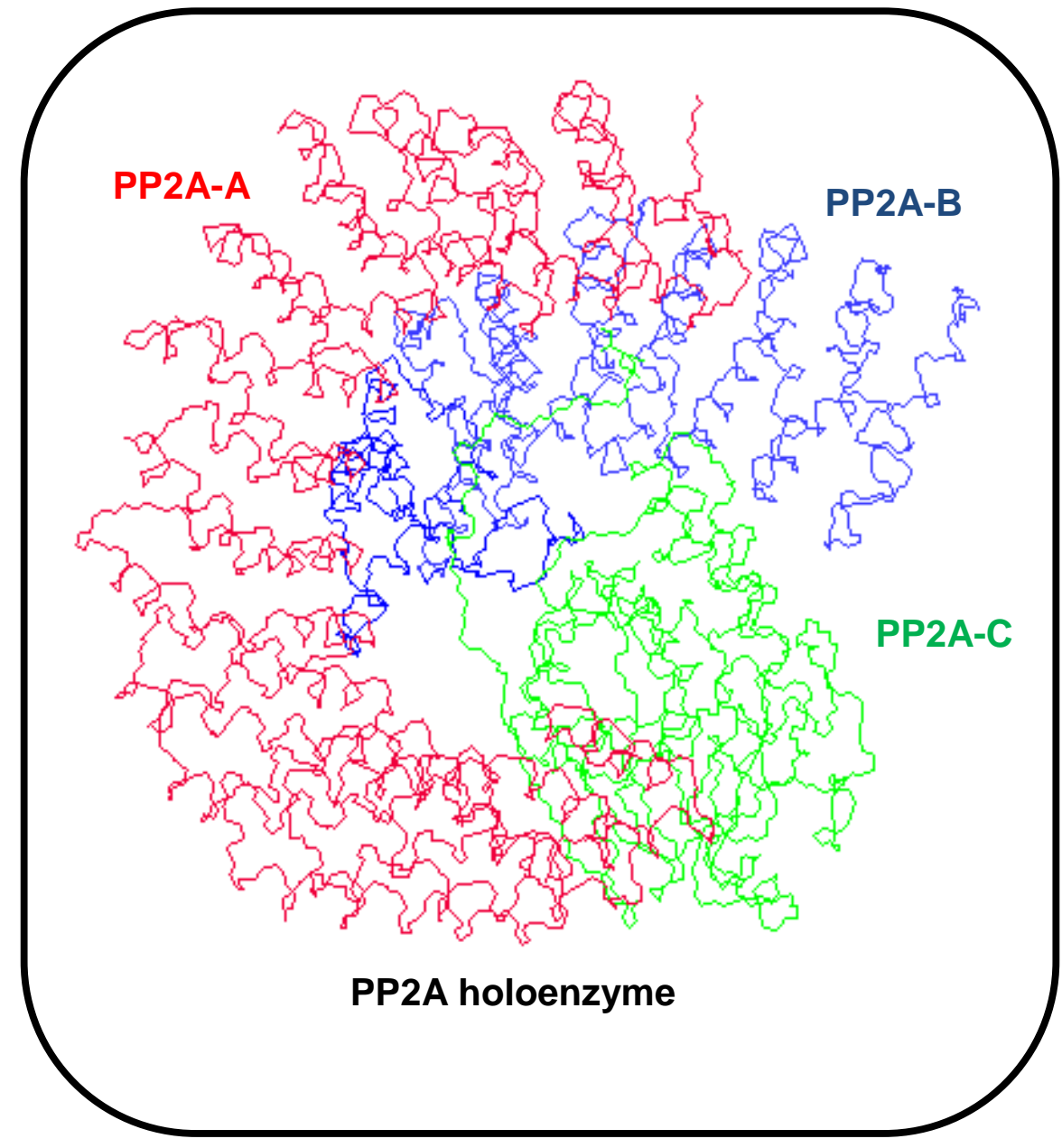

Figure 10 Structure of PP2A tetramer

Structure is drawn from the PDB file 2IAE from the protein databank. Three main domains of PP2A tetramer - PP2A-A, PP2A-B and PP2A-C are shown in red, blue and green respectively. 


\section{(c) Alleles of PP2A:}

In Drosophila, not all of the components of PP2A have been characterized. Only the structural subunit (PR65), the catalytic subunit (PP2Ac), and two of the regulatory subunits (PR55 $[B]$ and PR61 [B']) have been identified. Among the various available mutants of PP2A the "microtubule star" ( $m t s)$ was used in this study. The mts mutant destroys the function of the catalytic subunit C. Because PP2A plays a role in microtubule attachment to the DNA during anaphase, this particular mutant displays microtubular arrays radiating from these multi-centromeric structures, looking similar to a 'star', hence the name "microtubule star' (mts). There are two mutant alleles of the structural subunit, called abnormal anaphase resolution (aar1) and twins $P$ which show abnormal wing imaginal discs (Bajpai et al., 2004; Mayer-Jaekel et al., 1992). Mutant alleles of these genes are available for studying. 


\section{Article II.}

Observing the effects of CK2 and PP2A on $\operatorname{In}(1) w^{m 4}$ and $T(2 ; 3) S b^{V}$ in Drosophila position effect variegation (PEV) 


\begin{abstract}
:
Drosophila melanogaster's genome, like all the other eukaryotes, is compacted into chromatin. Chromatin can be divided into two main types, heterochromatin and euchromatin. Several lines of evidence suggest that compaction into heterochromatin usually prevents a gene's expression. X-chromosome inactivation in placental mammals is one of most important examples of this kind of gene inactivation (Lyon, 1961). The dynamics of compaction into either heterochromatin or euchromatin can be investigated in $D$. melanogaster using a type of aberration referred to as Position Effect Variegation (PEV). PEV is the result of a reporter gene being displaced from its normal euchromatic chromosomal location to one very close to heterochromatin. Adjacent heterochromatin can spread and inactivate the reporter gene. In this section we studied the effects of the wellknown kinase CK2 on two different PEV reporter genes - white and Stubble. Also, we studied the effects of the phosphatase PP2A on chromatin modification by using a variegating white reporter gene. Several PEV modifiers with putative CK2 phosphorylation sites were selected to determine dominance and/or epistasis of these modifiers relative to CK2 mutants.
\end{abstract}




\section{Introduction:}

In this thesis the model organism is Drosophila melanogaster, the common fruit fly. For over a century it has been a very useful tool to study genetics and other biological questions. Early in 1900's, Thomas Hunt Morgan, started working with flies. With his discovery of sexlinkage and genetic recombination, the fruit-fly started their journey to becoming a critical model system for investigating questions in fields as diverse as behavior, development, disease and genetic manipulation. The short life-cycle, easy handling in the lab, the large number of readily available mutants, the sequenced genome, and similarity with human genome are some of the reasons Drosophila has been so thoroughly studied. A large segment of the typical eukaryotic genome is packed into highly condensed constitutive heterochromatic blocks which can be deeply stained during the metaphase to interphase transition (Allis et al., 2007). These blocks are mainly associated with the telomeric or centromeric region of the chromosomes (Figure 3). These heterochromatic regions are late replicating with little or no meiotic recombination and they also contain very few genes (Allis et al., 2007). In Drosophila, about one-third of the genome is heterochromatic including $40 \%$ of the pericentromeric $X$-chromosome; the entire $Y$ chromosome; and $20 \%$ of the

pericentromeric large autosomes (Allis et al., 2007). Drosophila has been used extensively during the past few decades to understand the biochemistry of heterochromatin formation and maintenance (Richards and Elgin, 2002). Muller in 1930 first identified white mutations in which the eye looked variegated with mixed patches of red and white facets.

The white gene product is required for normal deposition of the eye pigments. In Drosophila, the wild type eye color is due to the presence of two pigments - pteridines that are red in color and ommochromes that are brown in color (Ephrussi and Herold, 1943). 
These pigments are deposited by a membrane-bound protein located within the photoreceptor cells (Yikang and Golic, 1998). In flies, the pigments are formed in different places, some near the gonads, and then transported to the eye. Thus variation in the eye color of the flies can result from defects in the genes that control the production of the pigments or in the transportation of the pigments (Yikang and Golic, 1998).

Muller's observations on the variegating white mutants led to the understanding that the white gene was not damaged because - (1) some facets remained red, indicating normal gene expression, and (2) the variegated phenotype could be reverted using X-ray mutagenesis (Allis et al., 2007). Several studies with polytene chromosomes revealed that the variegated phenotypes were the consequences of chromosomal rearrangements - an inversion, that caused one breakpoint in the pericentromeric region and the other one close to the white gene (Tartof et al., 1984). Because this phenotype was caused by the change of the positioning of the gene within the chromosome, the phenomenon was referred to as position effect variegation or PEV. PEV mutants have been studied in yeasts and mammals as well (Talbert and Henikoff, 2000). One of the most useful PEV rearrangements is the $\ln (1) w^{m 4}$. In this inversion the white gene is juxtaposed to the X-chromosomal heterochromatic material located on the distal border of nucleolus organizer (Cooper and Hausman, 1959). This region also contains the R1 type of rRNA repeating units (Tartof et al., 1984). Several studies have shown this repetitive DNA to be the target of heterochromatin formation (Reuter and Spierer, 1992).

Because we want to see the effect of CK2 and PP2A mutants on PEV, we chose to work with two well-known PEV reporter genes - the white gene, and the dominant mutation Stubble, that affects bristle length. 
In Drosophila, there are several modifiers of PEV, that can either suppress the silencing [Suppressors of variegation or Su(var)] or can enhance the silencing [Enhancer of variegation or $\mathrm{E}(\mathrm{var})]$. There are about $140 \mathrm{Su}(\mathrm{var})$ and $230 \mathrm{E}(\mathrm{var})$ mutations isolated so far (Schotta et al., 2003). In general, duplication of heterochromatic sequences causes suppression of variegation, whereas deletion of such sequences can enhance the silencing. These effects might be due to there being a fixed amount of proteins available for compaction of DNA into heterochromatin and the altered amount of heterochromatic sequences will alter the amount of these factors available for PEV inactivation. The Su(var) and $E$ (var) mutations identify the genes that determine the extent of heterochromatin gene silencing. In most cases the modifying effects on PEV mutations are dominant. There are some modifiers - like Su(var)3-7 (encoding Zinc-finger containing protein), Su(var)3-9 (encoding histone lysine methyl transferase) which also show dosage dependent effects on PEV (Schotta et al., 2003).

Several previous studies revealed that many well known PEV modifiers such as Heterochromatin protein 1 (HP1) (Zhao and Eissenberg, 1999) and the GAGA factor (Boneta et al., 2005) are phosphorylated by CK2 and thus chromatin modifications have been modulated accordingly. An examination of the coding sequences for other modifiers of PEV revealed that many had putative CK2 phosphorylation sites that were often evolutionarily conserved. This leads us to investigate other PEV modifiers with putative CK2 phosphorylation sites in combination with CK2 mutations. This will provide insights to the epistatic relationships between CK2 and PEV modifiers. We studied the effects of wellknown kinase CK2 mutants on two different PEV reporter genes - white and Stubble. Both the white and Stubble genes have been extensively studied revealing aspects of Drosophila 
PEV (Bishop, 1992; Tartof et al., 1989). The variegating mutants used to examine the direct effects of CK2 mutants on PEV were $\ln (1) w^{m 4}$ and $T(2 ; 3) S b^{V}$. In a separate study, the effects of mutants for the phosphatase PP2A, thought to antagonize CK2 effects, were also examined using $\ln (1) w^{m 4}$.

Following are the specific aims studied in this thesis -

Aim 1: Effect of CK2 and PP2A using white as a reporter gene
A) Effect of CK2 on the PEV reporter $\ln (1) w^{m 4}$
B) Effect of PP2A on the PEV reporter $\ln (1) w^{m 4}$

Aim 2: Effect of CK2 in combination with other PEV modifiers using white as a reporter gene

Aim 3: Effect of CK2 using Stubble as a reporter gene - Testing the role of CK2 on PEV by using the Stubble reporter gene 


\title{
Aim 1: Effect of CK2 and PP2A and HP1 on PEV using white as a reporter:
}

\section{A) Effect of CK2 on the PEV reporter $\ln (1) \mathrm{w}^{m 4}$ in the presence and absence of an allele of HP1}

Earlier studies with HP1 (Eissenberg and Elgin, 2000; Zhao et al., 2001a) have already shown that this well known PEV modifier has a putative CK2 phosphorylation site that when mutated to a phosphomimetic version, mimicking CK2 phosphorylation, has an altered effect on PEV. This leads us to examine the effect of CK2 mutants on PEV or chromatin modification in the presence of HP1 mutants. We observed the effects of CK2 mutants in combination with an HP1 mutant on the white reporter gene in $\ln (1) w^{m 4}$, which, as described earlier, is expressed in the eye. Two CK2 alleles - Tik and Tik ${ }^{R}$ were used for the study.

B) Effect of PP2A on the PEV reporter $\ln (1) \mathrm{w}^{\mathrm{m} 4}$ in the presence and absence of a mutant allele of HP1

Next we wanted to see the effect of the well known phosphatase - PP2A with the same HP1 allele again using $\ln (1) w^{m 4}$ as our PEV reporter. Here, we observed the antagonistic role of the kinase and phosphatase on PEV.

\section{Method:}

\begin{abstract}
A) Effect of CK2 on PEV in the presence and absence of an HP1 mutant allele:
To observe the effect of CK2 on PEV, three individual sets of genetic crosses were set up between the three CK2 alleles - CK2-alpha-Tik, CK2-alpha- Tik ${ }^{R}, C K 2-M B$ with $\operatorname{In}(1) w^{m 4}$ (hereafter referred as $w^{m 4}$ ) as the PEV reporter. The $w^{m 4}$ stock also contained an allele of
\end{abstract}


HP1. The $w^{m 4}$; Su(var)204/CyO stock was obtained from the Bloomington Stock Center (stock \# 6234). All the crosses were performed and maintained at $25^{\circ} \mathrm{C}$.

\section{Crossing scheme to observe the effect of CK2 alleles on PEV on $w^{m 4}$ by using HP1 modifier:}

Female virgins of $w^{m 4}$; Su(var)-204/CyO were crossed with the $w / Y$; Tik/TM3,Sb; $w / Y$; $C K 2 M B / T M 3, S b$ or $w / Y$; $T_{i k}^{R} / T M 3, S b$ males at $25^{\circ} \mathrm{C}$. In the $\mathrm{F} 1$ generation the double heterozygous flies carrying alleles of HP1 and Tik, Tik ${ }^{R}$, or CK2-MB ( $w^{m 4}$; Su(var)204/+; CK2 allele/+) would examine the effects of CK2 on HP1 modifier, whereas the single heterozygotes would be the internal controls for CK2 alleles $\left[\mathrm{w}^{\mathrm{m} 4} ; \mathrm{CyO} /+\right.$; CK2 allele (Tik, $\mathrm{Tik}^{R}$ or $\left.\left.\mathrm{CK} 2 \mathrm{MB}\right) /+\right]$ and HP1 [ $w^{m 4}$; Su(var)204/+; TM3, Sb/+] respectively. The $w^{m 4} ; \mathrm{CyO} /+$; TM3, Sb/+ flies would be an internal control for the variegated eye phenotype in the absence of modifiers. All these flies were separated by genotype and sex, aged for five days at $25^{\circ} \mathrm{C}$ and assayed for red eye pigmentation.

\section{B) Effect of PP2A on PEV in the presence and absence of an HP1 mutant allele:}

\section{Crossing scheme to observe the effect of PP2A allele on PEV on $w^{m 4}$ by using HP1 modifier:}

The PP2A mutant, $m t s$, was used as the Loss-Of-Function PP2A allele. $m t^{X E-2258} / \mathrm{CyO}$, $P\{$ sevRas1.V12\}FK1 (Bloomington stock \# 5684 and here after referred as mts/CyO[FK1]) was used for the study. Flies from the PP2A-mts stock were crossed with the $w^{m 4}$; Su(var)204/CyO flies to determine the effects of reduced phosphatase activity on PEV and the epistatic relationship between PP2A and HP1. The crosses were performed and maintained at $25^{\circ} \mathrm{C}$. 
In the F1 generation, the doubly heterozygous flies with PP2A mutant allele $m t s$ and the HP1 allele Su(var)-204 would indicate epistatic test of one modifier alone. The flies with the genotype $w^{m 4} ; C y O /+$ will be the control showing only $w^{m 4}$ phenotype. Flies were separated as indicated below and red eye pigmentation assay was conducted.

\section{Red eye pigmentation assay to measure the effect of PEV:}

Red eye pigmentation was assayed by modifying the method used by Ephrussi et. al. in 1943. Newly eclosed flies were collected and sorted according to the appropriate sex and genotype. The flies were placed in separate food vials according to their sex and aged five days to insure that all the eye pigments have been deposited. After ageing, the flies were collected in $1.5 \mathrm{~mL}$ micro centrifuge tubes and frozen using liquid nitrogen. The tubes were then vigorously agitated using a vortex for roughly 30 seconds for the clean separation of the head from the rest of the body. The heads were stored at $-80^{\circ} \mathrm{C}$. Ten heads were placed in a $0.5 \mathrm{~mL}$ micro centrifuge tube according to sex and genotype. The assay, unless otherwise noted, was performed with three eppendorf tubes each containing 10 heads of a particular sex and genotype, thus having 3 replicas for each type. Two hundred microliter of Acidified Ethyl Alcohol (AEA) [AEA $=150 \mathrm{uL} \mathrm{HCL}+7.5 \mathrm{~mL} 100 \% \mathrm{ETOH}+\mathrm{H}_{2} \mathrm{O}$ to $25 \mathrm{~mL}$ ] were added to each of the tubes and the isolated heads were shaken on a C1 Platform Shaker (New Brunswick Scientific) for 48 hours in the dark at room temperature (RT) to extract the red pigments. After 48 hours of shaking, the tubes were centrifugated at $12,800 \mathrm{~g}$ for ten minutes and the supernatant was then transferred to another clean micro centrifuge tube without disturbing the pellets. The absorbance was taken at $480 \mathrm{~nm}$ using a microcuvet to determine the amount of red pigment extracted from the heads. The readings were 
recorded for each replica and for each type according to different sexes and genotypes. All the data were recorded and analyzed to observe the effects on red eye pigmentation by using the ANOVA statistical analysis. The p-values were obtained to identify any statistically significant differences. The $p$-values are mentioned in the respective graphs.

\section{Blind study between Tik and Tik ${ }^{R}$ crosses to verify the role of CK2 on PEV:}

The eye pigment assay necessitates the sorting out and collection of fly heads by hand. To eliminate any unintentional bias in this study and to make sure that the data are reproducible, a double blind study was performed. In this portion of the study the crosses were set up by a third party, where the three replicas for each type of cross were labeled with specific letters, so that the identities of the parents were kept secret. In that way, crosses with HP1-Tik and HP1-Tik ${ }^{R}$ were impossible to recognize and thus the results will be unbiased.

\section{Results and Discussions:}

\section{(a) Analyzing the role of CK2 and PP2A on PEV by studying HP1 mutant allele}

\section{Su(var)205 with $w^{m 4}$ as the reporter:}

As mentioned earlier, the CK2- $\alpha$-Tik is a dominant negative (DN) allele of CK2 with $<50 \%$ CK2 activity. Su(var)-204 is an allele of HP1. As the result of the genetic crosses mentioned in the method section, the various CK2 mutant males ( $T i k, C K 2 M B$, and $\left.T i k^{R}\right)$ were crossed with HP1 female flies in three different sets of experiments, each having three replicas. The

resultant $\mathrm{F} 1$ female flies with the genotype $w^{m 4} / w ; C y O /+; T M 3, S b /+$ were the internal control which show the normal mottling effects of $w^{m 4}$. The $w^{m 4}$; Su(var)204/+; TM3, Sb/+ 
flies are another internal control which show the HP1 effects on mottling. Because HP1 is a well known Su(var), the flies which are heterozygous for HP1 - Su(var)204, show more red pigment compared to those with $w^{m 4} ; \mathrm{CyO} /+; \mathrm{TM} 3, \mathrm{Sb} /+$ genotypes. According to the hypothesis, if CK2 would have any effect on PEV, the $w^{m 4} ; \mathrm{CyO} /+$; $\mathrm{Tik}^{\mathrm{m}}+$ or $w^{\mathrm{m} 4} ; \mathrm{CyO} /+$; $C K 2 M B /+$ or $w^{m 4} ; C y O /+; T^{R} /+$ flies will have different mottling effects on the variegated eyes compared to the internal controls.

(i) Analyzing the effect of CK2 on PEV:

\section{1) Analyzing the effect of Tik on PEV:}

In this study we observed $w^{m 4} ;$ CyO/+; Tik/+ flies (Figure: 11B) have less red eye pigmentation compared to the $w^{m 4} ; \mathrm{CyO} /+; \mathrm{TM} 3, \mathrm{Sb} /+$ (Figure: 11D) flies. The red eye pigmentation assay also verifies the reduced amount of red pigments in the presence of Tik (Figure: 14). This result suggests that Tik is acting as an enhancer of PEV or E(var). Even the doubly heterozygous flies with HP1 and Tik together [w ${ }^{m 4}$; Su(var)204/+; Tik/+], have less red eye pigments (Figure: $11 \mathrm{~A}$ ) compared to the ones with $w^{m 4} ; \mathrm{CyO} /+; \mathrm{TM} 3, \mathrm{Sb} /+$ (Figure:26 D) and $w^{m 4}$; Su(var)204/+; TM3, Sb/+ (Figure: $11 \mathrm{C}$ ). This suggests the enhancing effect of Tik as an E(var) is dominant over the suppressing effect of HP1. The enhancing effects of the dominant negative allele of CK2-Tik, suggest that CK2 must play a role in maintaining the euchromatic state and reducing CK2 activity permits the formation of more heterochromatin.

\section{2) Analyzing the effect of CK2MB on PEV:}

Flies from the cross between $C K 2 M B^{00117}$ males and HP1- Su(var) 204 females did not, however, show any enhancing or suppressing effects of CK2MB ( Figure: 12B). When 
comparing flies with the genotypes $w^{m 4} ; \mathrm{CyO} /+; C K 2 M B /+$ to that of the internal control $w^{m 4}$; $\mathrm{CyO} /+; \mathrm{TM} 3, \mathrm{Sb} /+$ (Figure: 12D) progeny, little difference in red eye pigmentation was observed. These results suggest that $C K 2 M B$ retains sufficient CK2 activity to function as wild type, which is not enough to show any PEV effects.

\section{3) Analyzing the effect of $T_{i k}^{R}$ on PEV:}

CK2-Tik ${ }^{R}$ is a revertant of the DN Tik and appears to be a complete loss of function allele. It was hypothesized that, like $C K 2 M B$, it would not show any strong effects on PEV. But surprisingly, from the cross between the Tik ${ }^{R}$ and HP1-Su(var)204 flies, the resultant $w^{m 4}$; CyO/+; Tik $/+$ flies show a strong suppressing effect. $T i k^{R}$ has a totally opposite effect compared to Tik. Tik ${ }^{R}$ suppresses variegation, having increased red eye pigmentation compared to those in $w^{m 4} ; \mathrm{CyO} /+; \mathrm{TM} 3, \mathrm{Sb} /+$ control flies (Figure: 13 and Figure: 16) while Tik has a strong enhancing effect. 


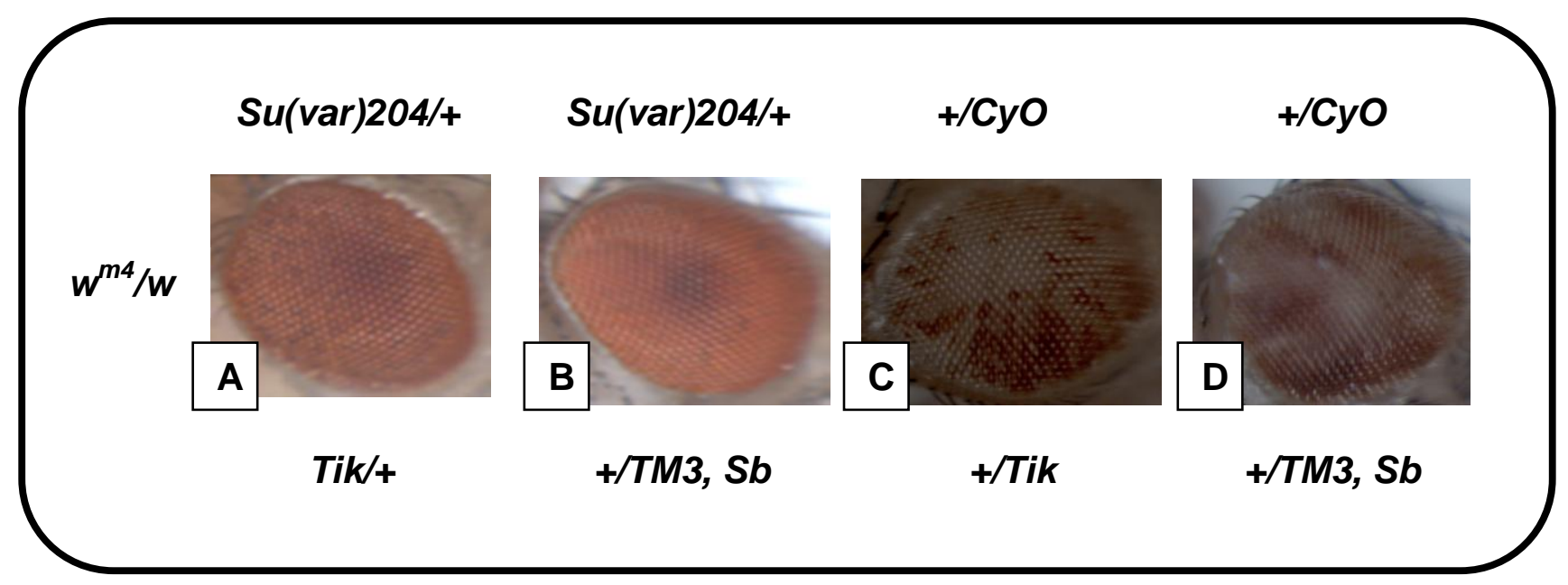

Figure 11 Effect of CK2-Tik on PEV.

A. Represents double heterozygous effect of both HP1Su(var)204 and Tik. B. Shows only the effects of HP1Su(var)204. C. Depicts Tik's effect on PEV. D. Serves as the control $w^{m 4} / w$ background. 


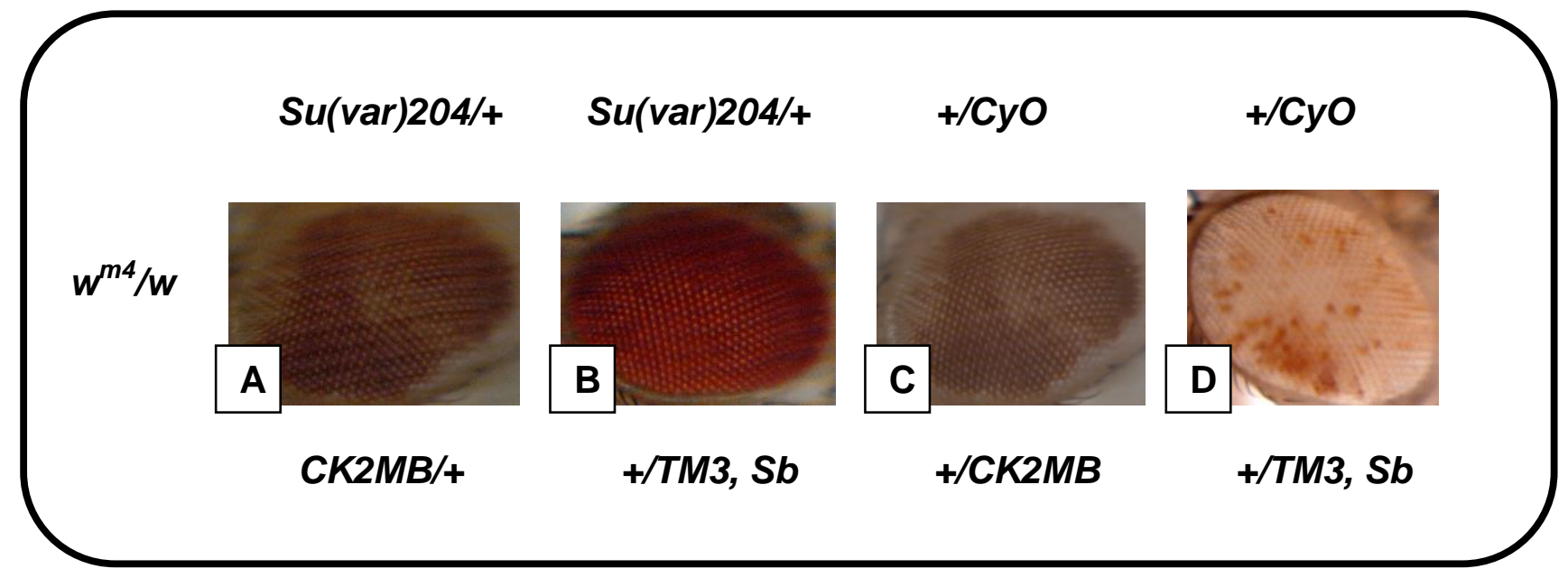

Figure 12 Effect of CK2MB on PEV

A. Represents double heterozygous effect of both HP1Su(var)204 and CK2MB. B. Shows only the effects of HP1Su(var)204. C. Reflects CK2MB effect on PEV. D. Serves as control for $w^{m 4} / w$ background. 


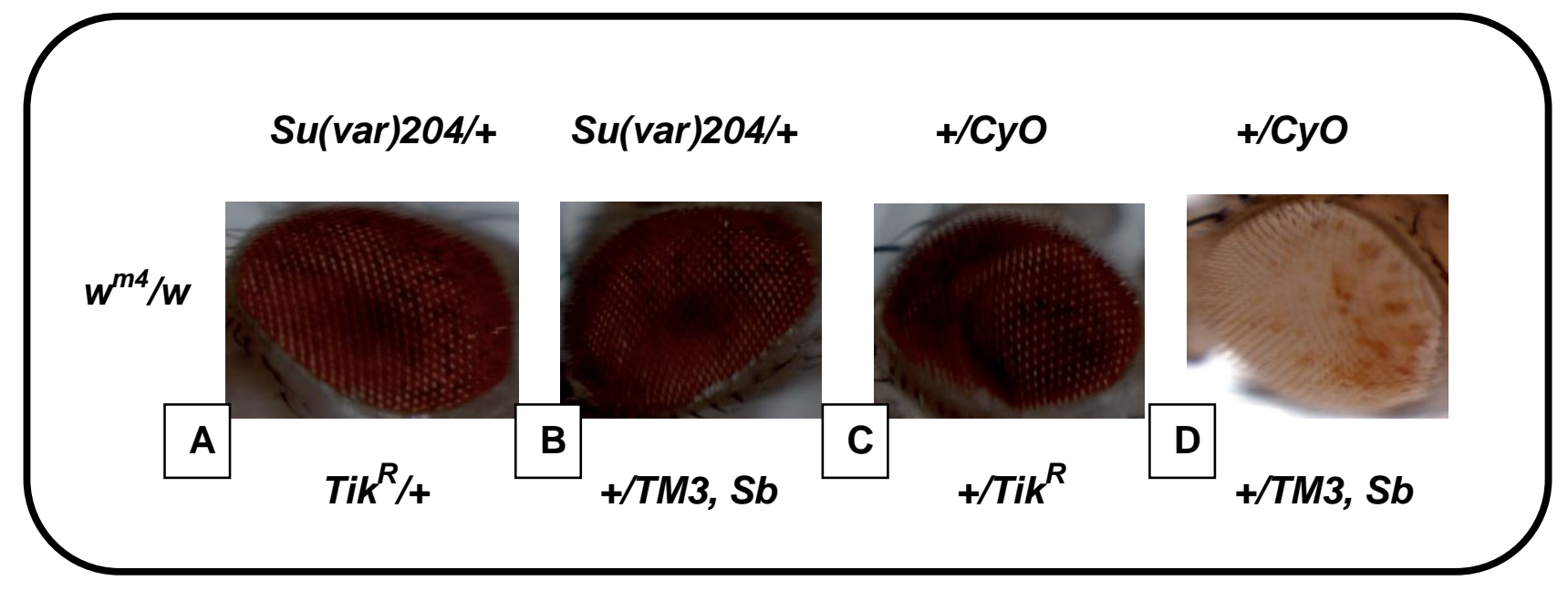

Figure 13 Effect of CK2-Tik ${ }^{R}$ on PEV

A. Represents double heterozygous effect of both HP1-

Su(var)204 and Tik ${ }^{R}$. B. Shos only the effects of HP1-

Su(var)204. C. Depicts Tik ${ }^{R}$ effect on PEV. D. Serves as

internal control in $w^{m 4} / w$ background. 


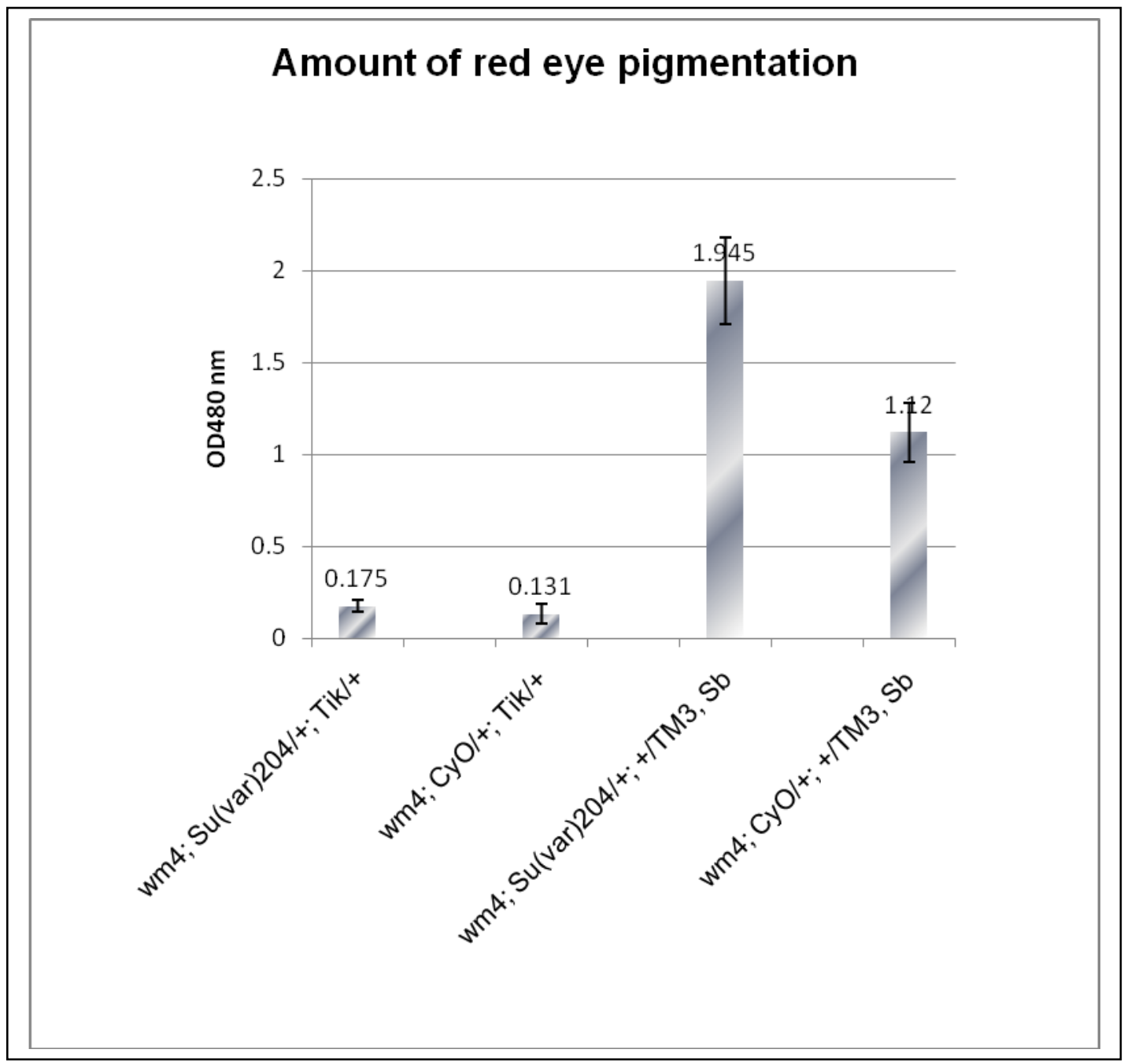

Figure 14 Red eye pigmentation assay result from the genetic cross between $w^{m 4} ; S u(v a r) 204 / C y O$ and $w / Y$;

Tik/TM3, Sb.

The mean of each trial according to the genotypes are shown in the graph with standard error bar. The ANOVA p-value is 0.0001 


\section{Amount of red eye pigmentation}

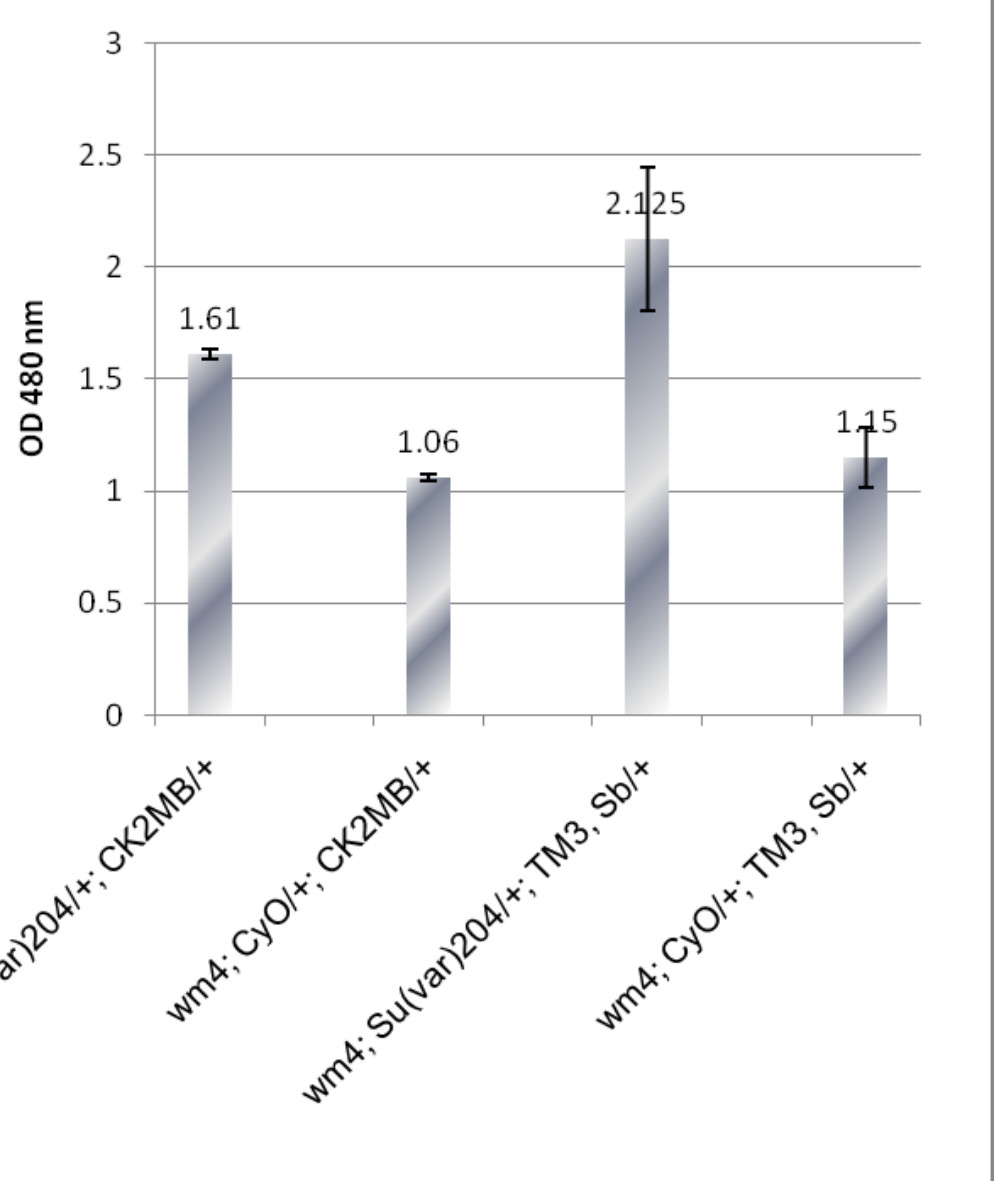

Figure 15 Red eye pigmentation assay result from the genetic cross between $w^{m 4}$; Su(var)204/CyO and w/Y; CK2MB/TM3, Sb.

The mean of each trial according to the genotypes are shown in the graph with standard error bar. The p-value from ANOVA is 0.014 . 


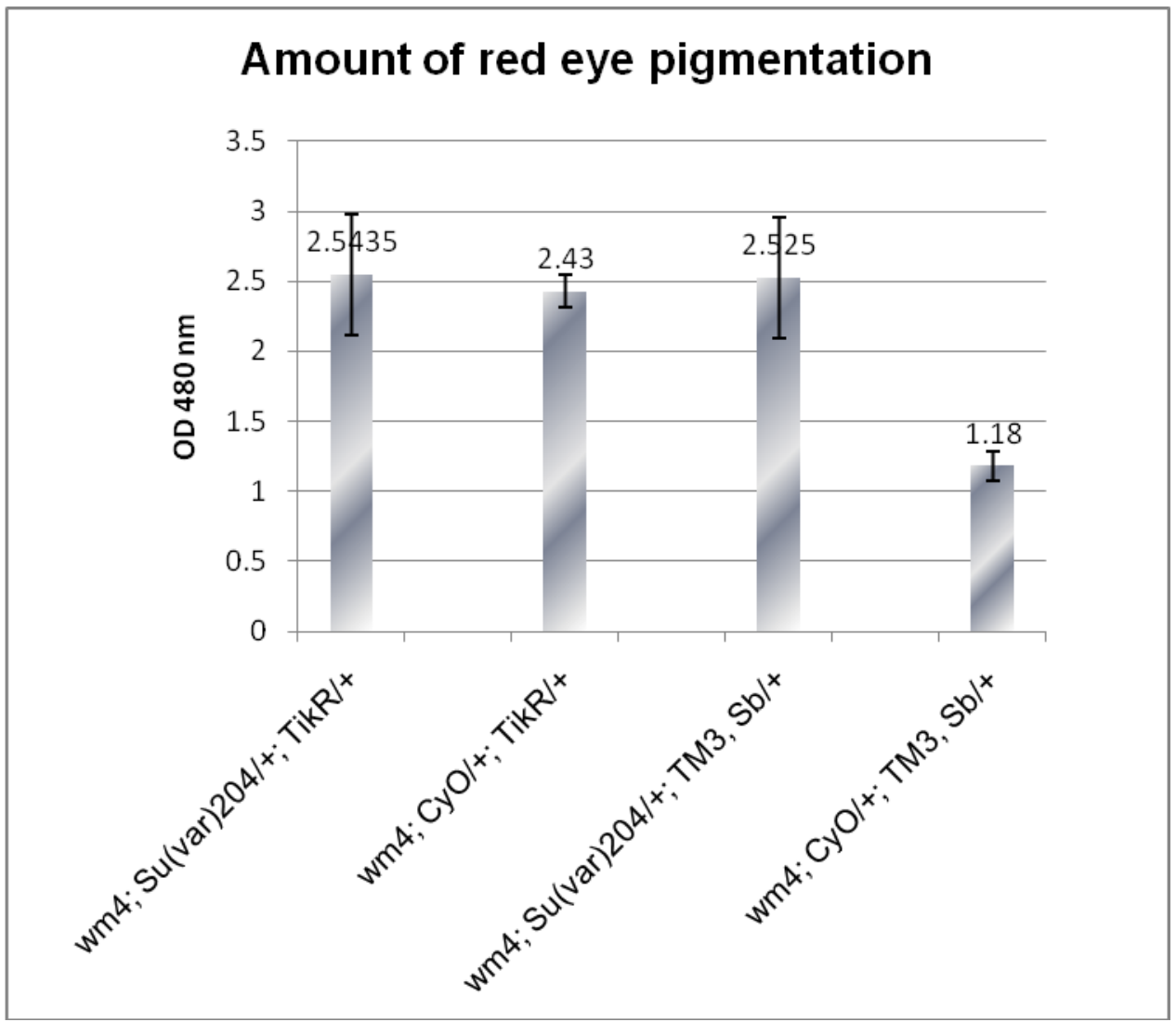

Figure 16 Red eye pigmentation assay result from the genetic cross between $w^{m 4}$; Su(var)204/CyO and w/Y; Tik ${ }^{R} / T M 3$, Sb.

The mean of each trial according to the genotypes are shown in the graph with standard error bars. The ANOVA p-value is 0.0011 . 


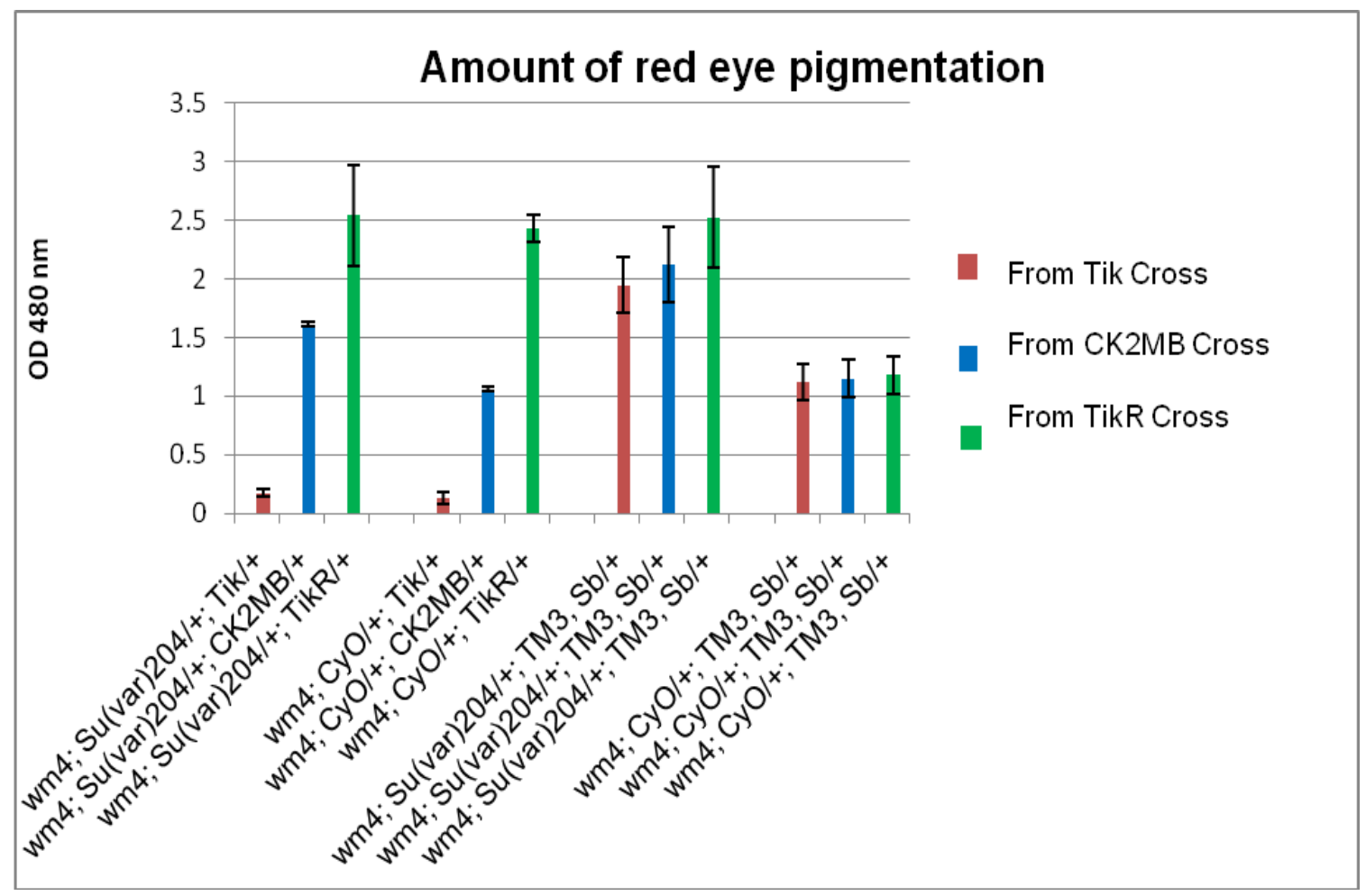

Figure 17 Combined red eye pigmentation assay result

Combined red eye pigmentation assay results (from figure 14-16) from the genetic crosses between $w^{m 4}$; Su(var)204/CyO with $w / Y$; Tik/TM3, Sb , w/Y; CK2MB/TM3, Sb and $w / Y$; $T k^{R}{ }^{R} / T M 3, S b$ in red, blue and green bars respectively. The mean of each trial according to the genotypes are shown in the graph with standard error bars. P-values are already listed in the previous figures. 


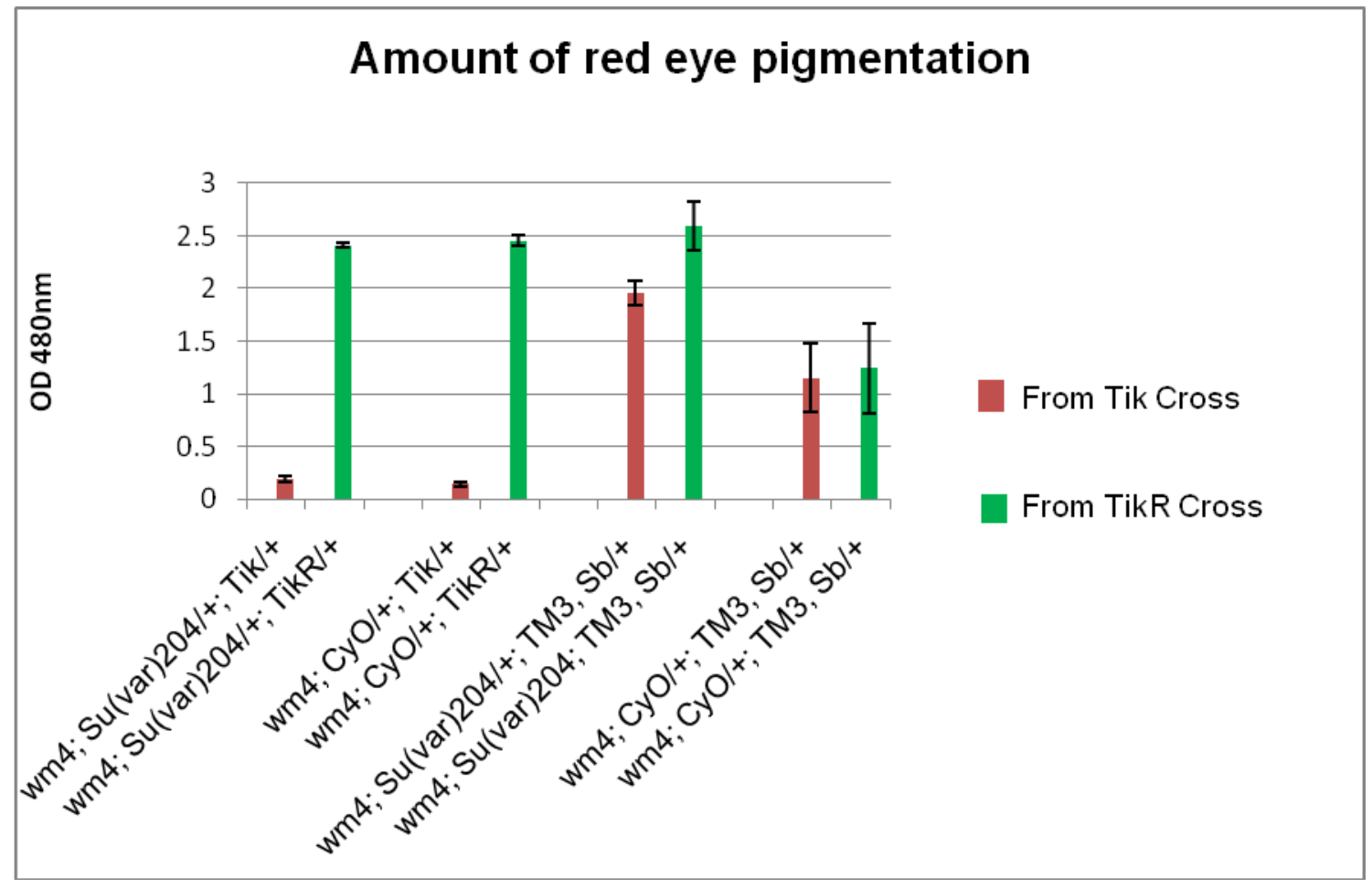

Figure 18 Combined red eye pigmentation assay result from the blind studies

Combined red eye pigmentation assay results from the blind studies for the genetic crosses between $w^{m 4}$; Su(var)204/CyO with $w / Y ; T i k / T M 3, S b$ and $w / Y ; T^{R} k^{R} / T M 3, S b$ in red and green bars respectively. The mean of each trial according to the genotypes are shown in the graph with standard error bars. All the values show similar trends as in previous studies shown in Figure 17. 
After the F1 flies from the double blind crosses eclosed, the female flies were sorted and aged according to their genotypes and red eye pigmentation assays were performed as discussed in the method section. The double blind study (Figure: 18) verified our earlier observations (Figure: 17)

(iii)

\section{Role of PP2A in chromatin structure:}

To observe the effects of PP2A, a serine-threonine phosphatase, a set of genetic crosses were conducted. As mentioned earlier, the HP1-Su(var)204 females were crossed, this time not with the CK2 alleles, but with the PP2A LoF allele mts. The crossing scheme is presented in the method section. The results from the F1 generation of this cross shows that, as anticipated, the heterozygous HP1 allelic flies ( $\left.w^{m 4} / w ; S u(v a r) 204 / S c o\right)$ in $w^{m 4}$ background have more red eye pigments (Figure: 19 and 20) than those in $w^{m 4} / w$; Sco/CyO. This serves as a control illustrating the Su(var) effects of HP1 in PEV. The $w^{m 4} / w^{\prime} m t s / C y O$ flies indicate the effect of $m t s$ in $w^{m 4}$ background. When compared with the $w^{m 4} / w ; S c o / C y O$ flies (Figure: 19D), the $m t s$ shows suppression of PEV effects in $w^{m 4} / w ; m t s / C y O$ females (Figure: 19C) resulting in more red pigments (Figure: 20). This depicts the Su(var) effect of $m t s$ on PEV suggesting that PP2A causes enhanced silencing or heterochromatinization.

The results as shown in the Figure: 19B and 19C, where both the HP1allele Su(var)204 and PP2A-mts heterozygous flies have similar modifying effects on PEV - suppressing the silencing of PEV. HP1 is known to code for a structural component of heterochromatin, that when mutated results in the formation of less heterochromatin. Our results suggest that PP2A may provide an essential role in the formation of heterochromatin. 


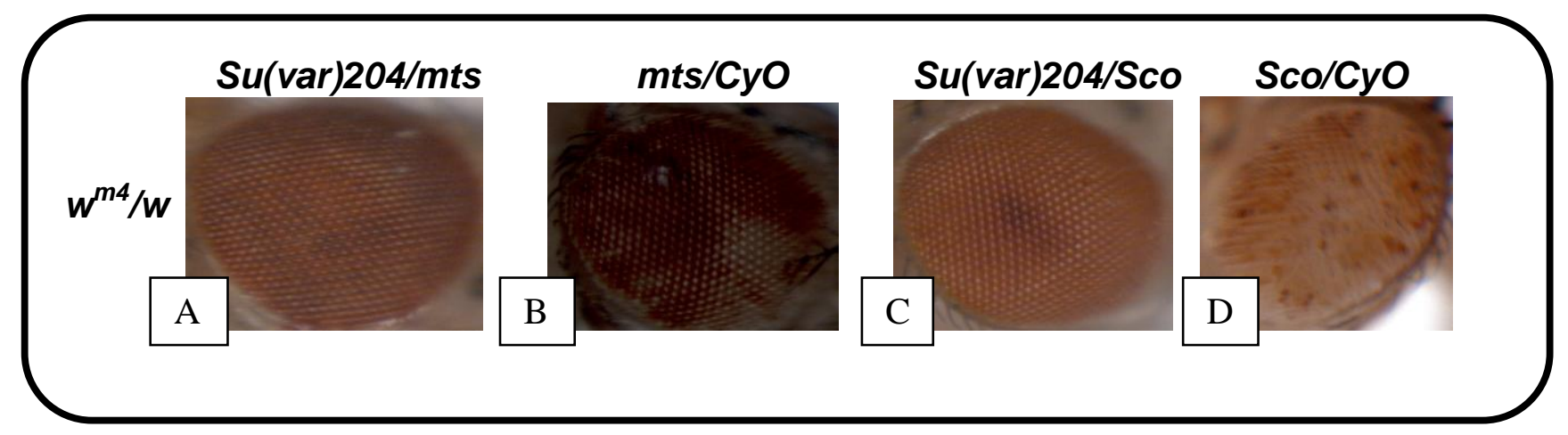

Figure 19 Effect of PP2A-mts on PEV.

A. Represents double heterozygous effect of both Su(var)204 and $m t s$. B. Shows only the effects of Su(var)204. C. Depicts $m t s$ effect on PEV. D. Serves as control with $w^{m 4} / w$ background. 


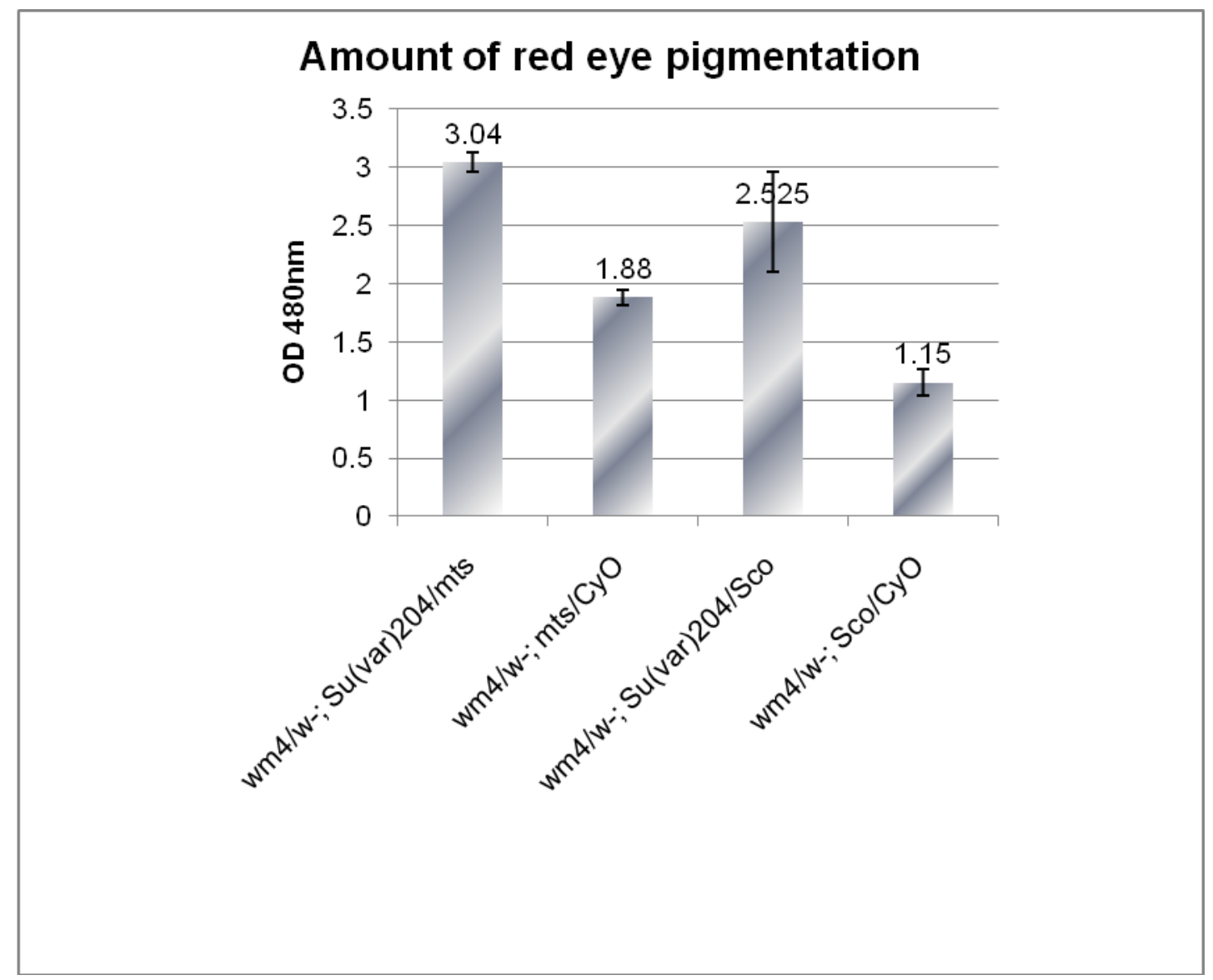

Figure 20 Red eye pigmentation assay result from the genetic cross between $w^{m 4}$; Su(var)204/CyO and w/Y; mts/Sco.

The mean of each trial according to the genotypes are shown in the graph with standard error bars and the p-value from ANOVA is 0.0007 . 
To further verify the mutant $m t s$ acts as a Su(var) for the $w^{m 4}$ reporter, we crossed the $m t s$ mutant with a previously known $\mathrm{E}(\mathrm{var})$ (Bloomington Stock \# 490; $w^{\mathrm{m4}} ; \mathrm{Df}(2 \mathrm{~L}) E 110 / \mathrm{CyO}$ ) to see if $m t s$ could counteract the enhancing effect of the $E$ (var). Our results in Figure: 22 indicate that the $E(v a r)$ is dominant to the $m t s$ effects..

Again, as there are a lot of modifiers throughout the genome, some enhancers may be activated by removal of a phosphate group, while others are inactivated. The same may hold true for suppressors of variegation. Each modifier would have to be tested individually to determine the role of PP2A and CK2. 


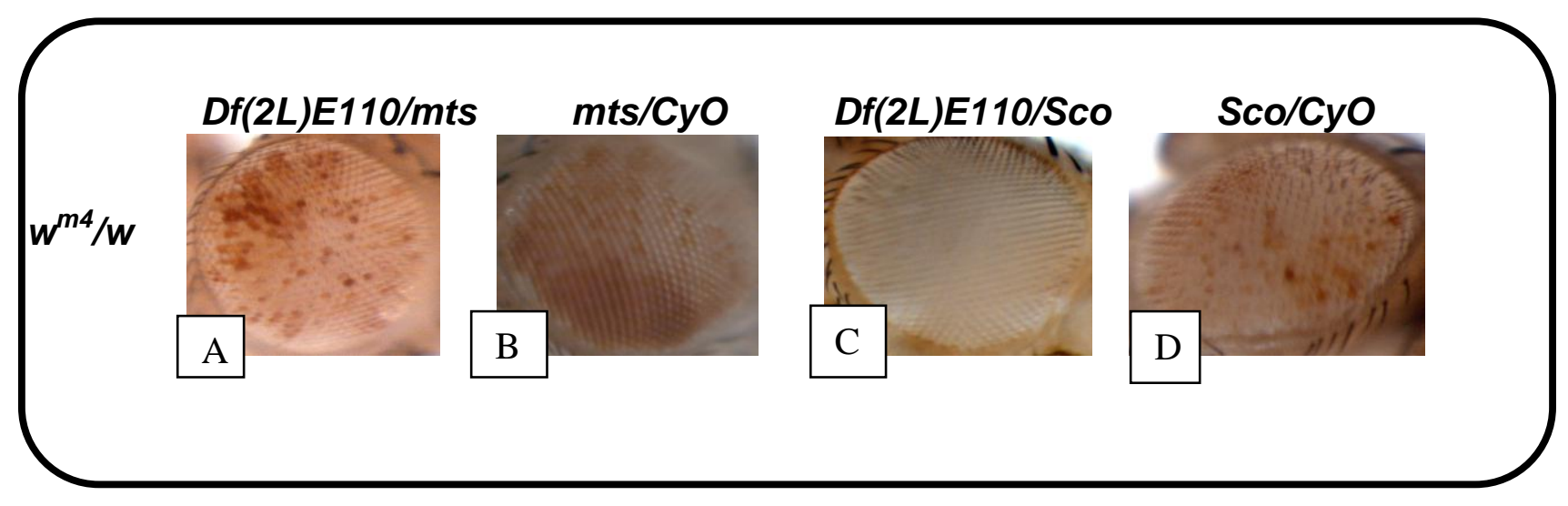

Figure 21 Effect of PP2A-mts on PEV.

A. Represents double heterozygous effect of both $E(v a r)$ and $m t s$. B. Shows only the effects of $m t s$. C. Depicts $\mathrm{E}$ (var) effect on PEV. D. Serves as control with $w^{m 4} / w$ background 


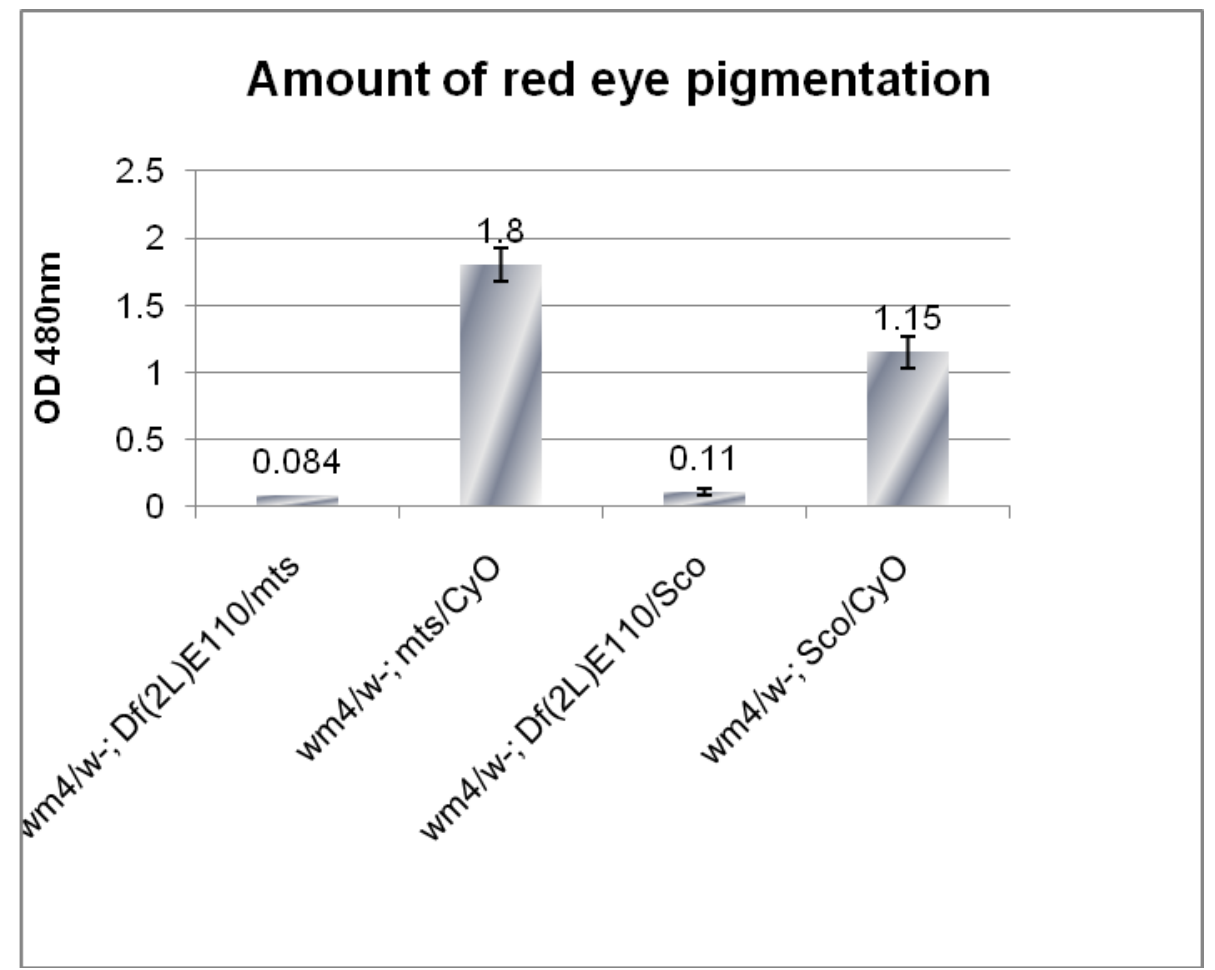

Figure 22 Red eye pigmentation assay result from the genetic cross between $w^{m 4} ; D f(2 L) E 110 / C y O$ and $w / Y ; \boldsymbol{m t s} / \mathbf{S c o}$.

The mean of each trial according to the genotypes are shown in the graph with standard error bars and the ANOVA p-value is 0.0004 . 


\section{Aim 2: Effect of CK2 in combination with other PEV modifiers using 'white' as a reporter:}

\section{Effect of CK2 on PEV in combination with other PEV modifiers:}

After the global function of CK2 on PEV was established via the well known PEV modifier HP1, we tested the ability of CK2 to modify chromatin effects with the other available PEV modifiers with putative CK2 phosphorylation sites.

A series of genetic crosses with the mutant alleles of these modifiers and the two CK2 mutant alleles were conducted. Any changes in the resultant F1 generations' eye pigmentation would indicate the epistatic relationship between CK2 and the other modifiers.

\section{Method:}

\section{Effect of CK2 on PEV in the presence of other PEV modifiers:}

Crossing Scheme to observe the effects of CK2 alleles combined with the PEV modifiers (second chromosome) on $w^{m 4}$ :

Female virgins of $w^{m 4}$; Tik/TM3, Sb Ser and $w^{m 4}$; Tik ${ }^{R} / T M 3$, Sb Ser were crossed with the males of the various second chromosomal modifier alleles $(w+/ Y ;$ Modifier/CyO). The second chromosomal modifiers that were studied were - Lamin, Piwi and dCAPG. From the resultant F1 generations of each of these crosses - the Curly and Stubble flies represented the internal control for $w^{m 4} ; \mathrm{CyO} /+; \mathrm{TM} 3, \mathrm{Sb} /+$. Compare to these, the non-Curly, Stubble flies ( $w^{m 4} ;$ Modifier/+; TM3, Sb/+) and the Curly, non-Stubble flies $\left(w^{m 4} ; C y O /+; C K 2\right.$ allele/t) were the representatives for the doubly heterozygotes of both the CK2 alleles and the modifiers ( $w^{m 4}$; Modifier/+; CK2 allele/+). 
Crossing scheme to observe the effects of CK2 alleles on PEV modifiers (third chromosome) on $w^{m 4}$ :

Female virgins of $w^{m 4}$; Tik/TM6B, Tb and $w^{m 4} ; T i k^{R} / T M 6 B, T b$ were crossed with the males of the various third chromosomal modifier alleles $\left(w^{+} / Y\right.$; Modifier/TM3, Sb).

The third chromosomal modifiers that were studied were - Reptin, Rpd3, Modulo and ORC2. From the resultant F1 generation of each of these crosses - males were collected and sorted according to their phenotypes. The Tubby, Stubble flies represented the internal control for $w^{m 4} / Y ; T M 6 B, T b / T M 3$, Sb. Compared to these, the non-Stubble, Tubby $\left(w^{m 4}\right.$; Modifier/TM6, Tb) and the non-Tubby, Stubble $\left(w^{m 4} ; C K 2\right.$ allele/TM3, Sb) flies were the internal controls of the respective modifiers and experimentals for the specific CK2 alleles respectively. The non-Tubby, non-Stubble ( $w^{m 4}$; Modifier/CK2 allele) flies were the representatives for the doubly heterozygotes of both the CK2 alleles and the specific modifiers.

\section{Results and Discussions:}

Role of CK2 with the different PEV modifiers on $w^{m 4}$ background: redefining the role of Tik as an $\mathrm{E}(\mathrm{var})$ :

To verify the role of Tik as an enhancer of PEV, we conducted a series of experiments with the different available second (Figure: 23) and third (Figure: 24) chromosomal PEV modifiers with putative phosphorylation sites (Gurudatta, 2010). The modifiers used are listed in the Method section.

To determine the effect of CK2 on the different modifiers, males carrying the different modifiers were crossed with the females of $C K 2$ alleles - Tik and Tik ${ }^{R}$, bearing the $w^{m 4}$ on 
their X-chromosomes. The resultant F1males heterozygous for the modifier alleles (Figure: 23, 24; Green box) are positive controls with increased red pigmentation because of the $\mathrm{Su}$ (var) effects of the modifiers. The yellow bordered figures represent the internal controls with only the $w^{m 4}$ phenotype. The single heterozygotes with Tik (red boxed figures in Figure: $23 \mathrm{~A}-\mathrm{C}$ and $24 \mathrm{~A}-\mathrm{D})$ show reduced red pigmentation, which indicate that Tik is an enhancer of PEV. Unlike Tik, the Tik ${ }^{R}$ chromosome displays an opposite role on PEV resulting in increased red eye pigment (red boxed figures in Figure: $23 \mathrm{D}-\mathrm{F}$ and $24 \mathrm{E}-\mathrm{H}$ ).

All these results again suggest Tik is a dominant enhancer of PEV but the role of Tik ${ }^{R}$ still remains a mystery. The red eye pigmentation assay results are shown in Figure 25 and 26. 


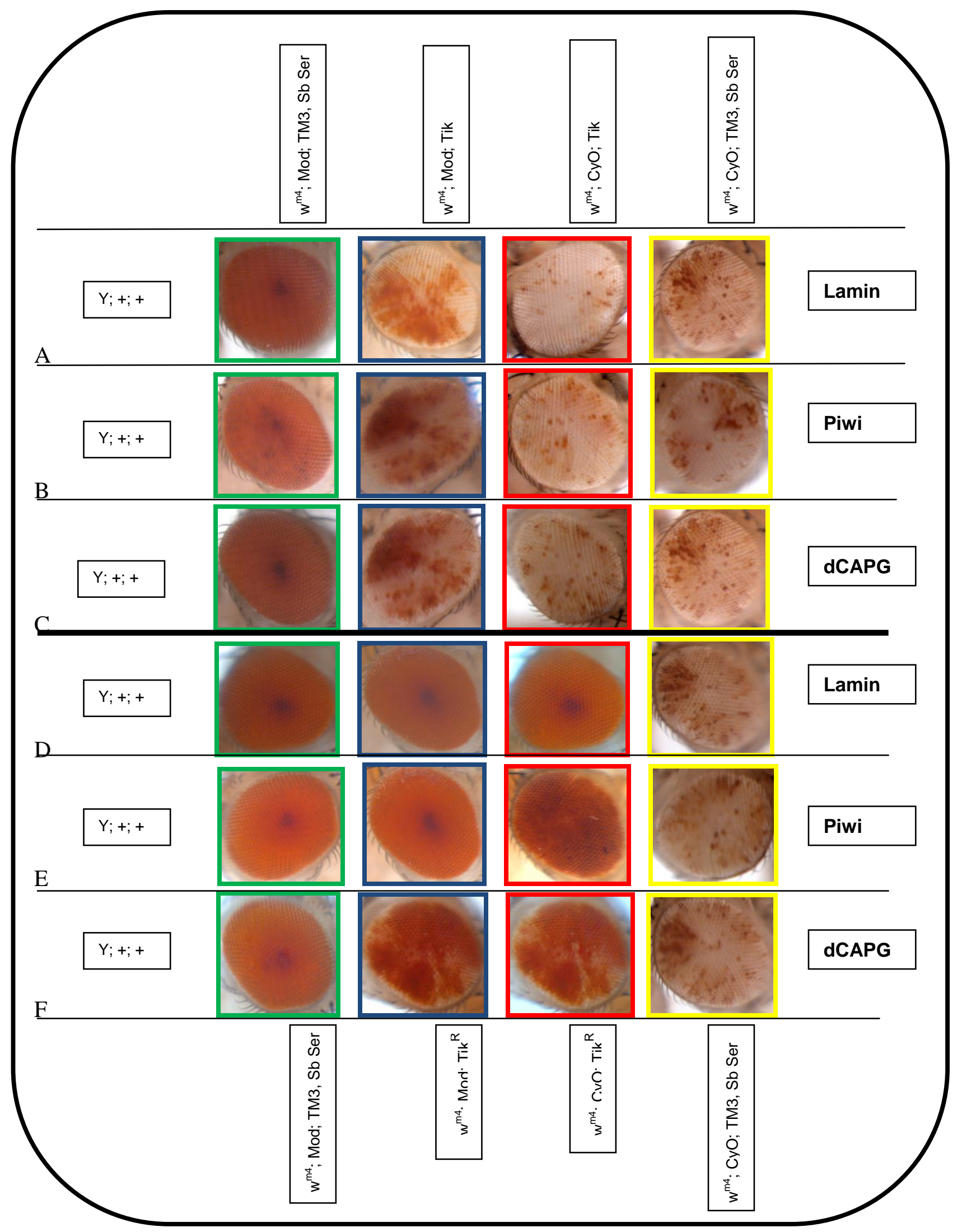

Figure 23 Effect of Tik and Tik ${ }^{R}$ on different second chromosomal modifiers of PEV The progeny between Tik (A-C) and Tik $^{R}(\mathbf{D}-\mathbf{F})$ and the indicated modifiers are shown. 


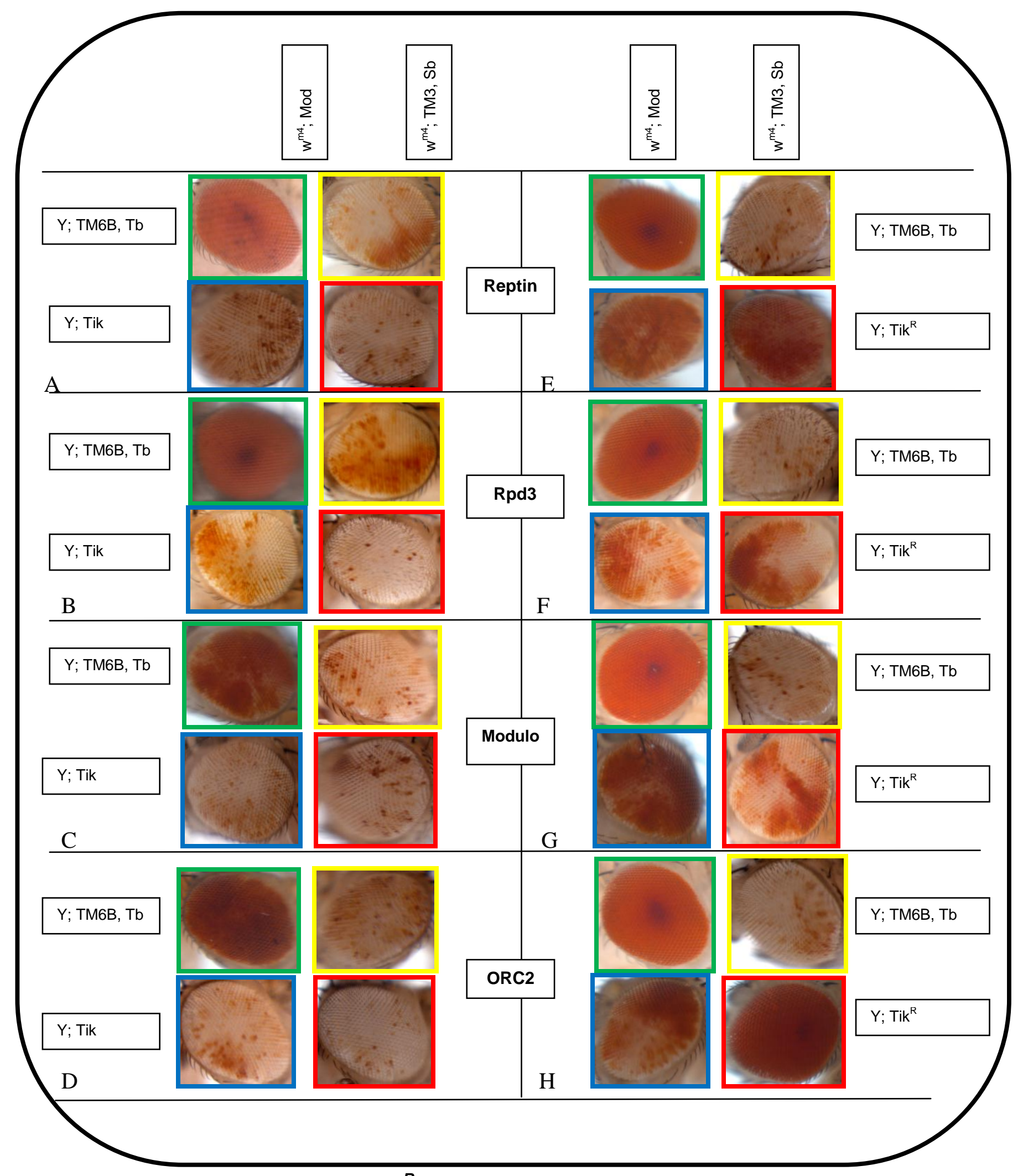

Figure 24 Effect of Tik and Tik ${ }^{R}$ on different third chromosomal modifiers of PEV The progeny between Tik (A-D) and Tik ${ }^{R}(\mathrm{E}-\mathrm{H})$ and the indicated modifiers are shown 


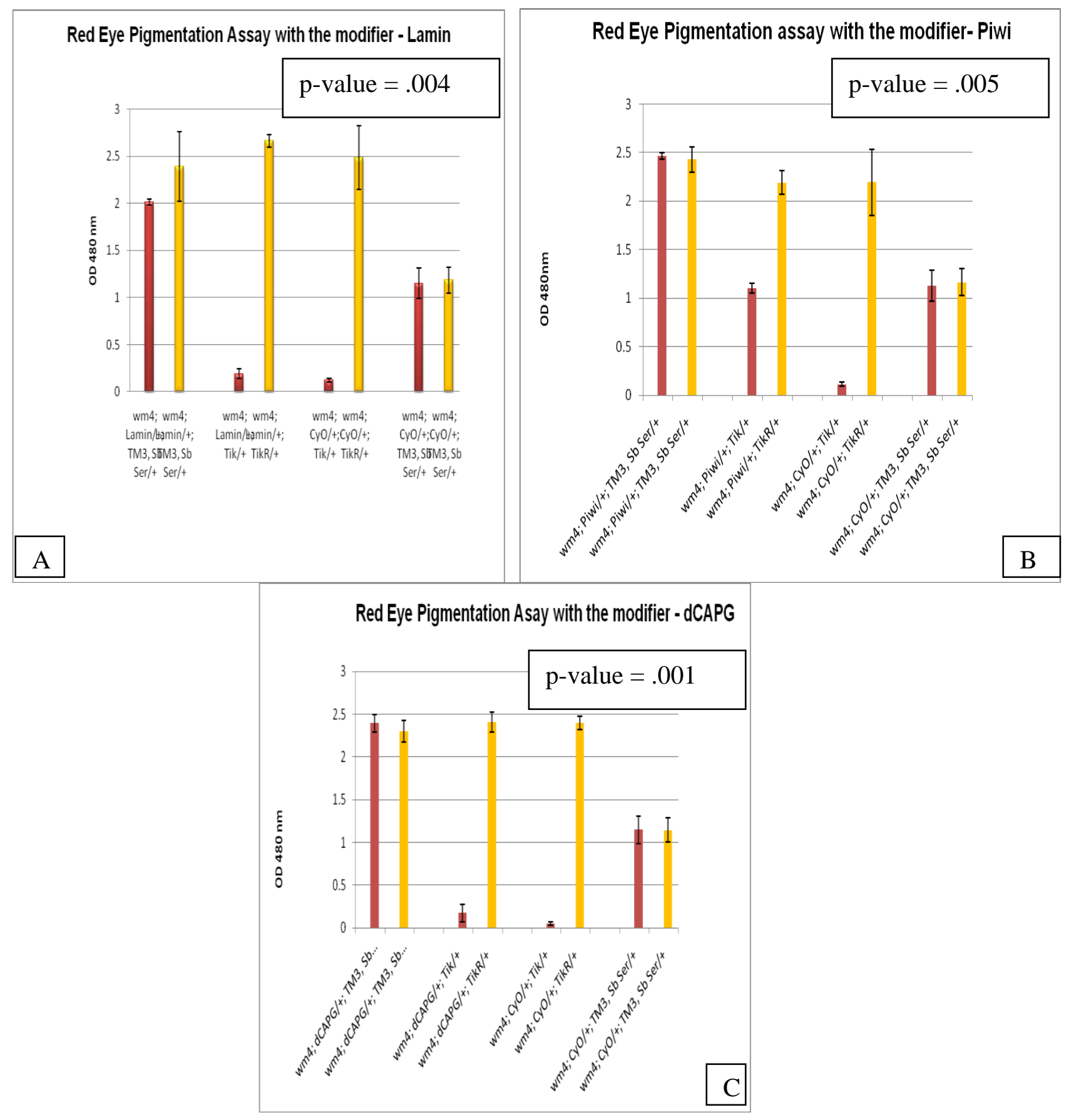

Figure 25 Red eye pigmentation assay results from the crosses with second chromosomal PEV modifiers and CK2 alleles Tik and Tik ${ }^{R}$.

A, $\mathbf{B}$ and $\mathbf{C}$ are the results with the modifier Lamin, Piwi and $d C A P G$ respectively. The red bars show the results from the cross with Tik, whereas the yellow bars represent the results from the $T i k^{R}$ crosses. 

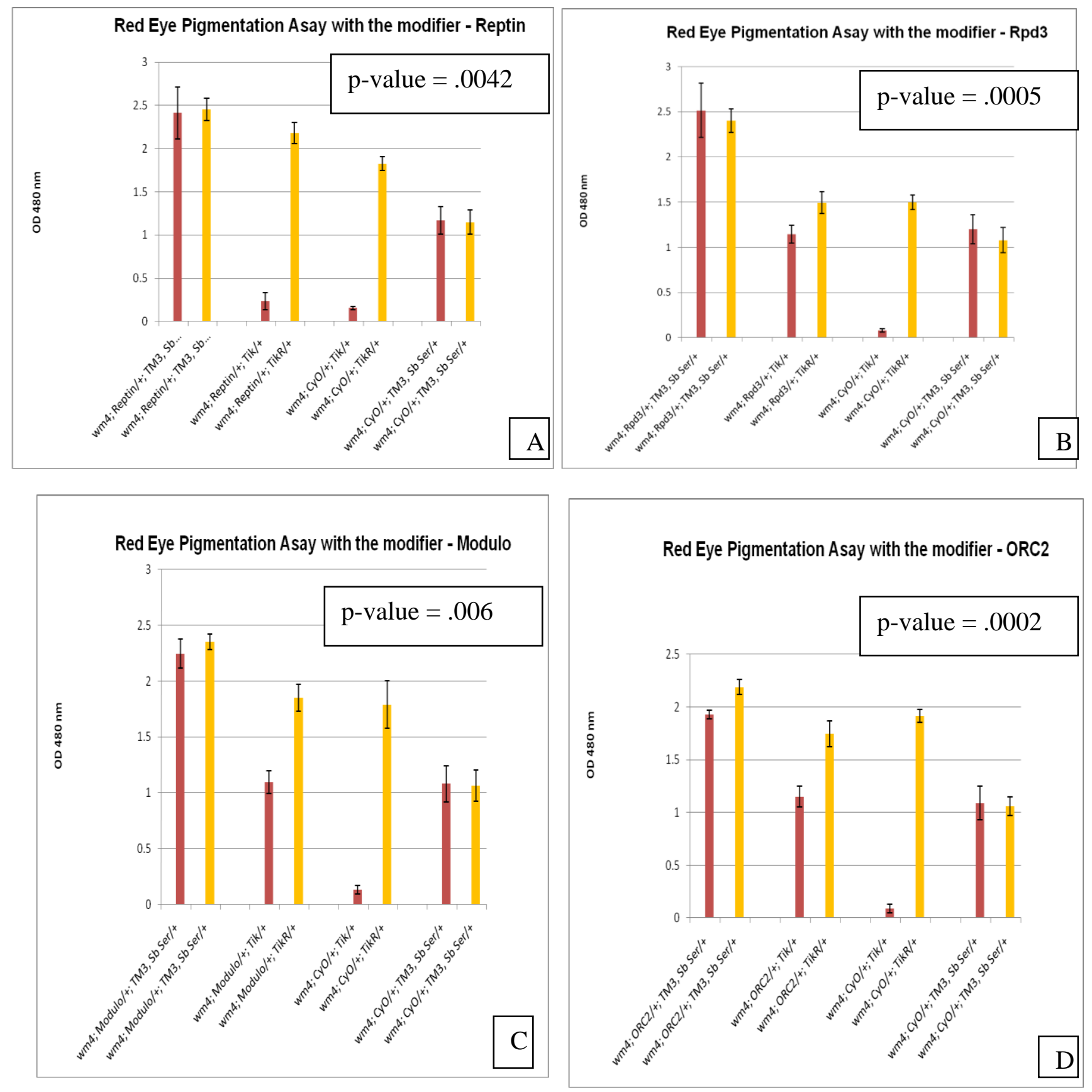

Figure 26 Red eye pigmentation assay results from the crosses with third chromosomal PEV modifiers and CK2 alleles Tik and Tik ${ }^{R}$

A, B, C \& D are the results with the modifier Reptin, Rpd3, Modulo and ORC2 respectively. The red bars show the results from the cross with Tik, whereas the yellow bars represent the results from the $T i k^{R}$ crosses. 


\section{Role of CK2-alpha Tik as a dominant PEV enhancer:}

Genetic crosses with Lamin, dCAPG and Reptin modifiers indicate that Tik can enhance PEV or silencing dominantly even when the suppressors are present. The figures 23 and 24 present the red eye pigmentation assays from the various genetic crosses with the indicated PEV modifiers and the Tik and Tik ${ }^{R}$.

From the F1 flies of these crosses, those that were non Curly, Stubble were subject to the effects of the modifiers. Because the lamin and $d C A P G$ are second chromosomal Su(Var)s, all the flies of this genotype (Figure: 25A, 25B) displayed more red pigment in the eyes when compared to the Curly, Stubble flies representing internal controls for $w^{m 4}$. The Curly, non-Stubble flies had less red pigment indicating enhanced silencing caused by the presence of Tik. Surprisingly, the non-Curly, non-Stubble flies, those that were doubly heterozygous for modifier alleles and Tik, show less red eye pigment compared to the single heterozygous modifier-only flies. These results suggest that the presence of Tik can cause dominant silencing of the white gene and that Tik is epistatic to Su(Var)s of PEV - Lamin and $d C A P G$.

These results are also apparent in the case of the genetic cross of the third chromosomal modifier Reptin and CK2-alpha Tik (Figure: 26A). Here also, the non-Curly, non-Stubble flies that were doubly heterozygous for Reptin and Tik, show much less red pigment making Tik a dominant enhancer of silencing over the suppressing effect of the Su(var) - Reptin. 


\section{Aim 3: Effect of CK2 using 'Stubble' as a reporter:}

\section{Testing the role of CK2 on PEV by using the Stubble reporter:}

The opposing results with the CK2 alleles compelled us to test the two CK2 alleles' effects on another PEV reporter system - T(2;3)S $b^{V}$. Unlike white, the Stubble effect was monitored in the bristles. Thus the effect of CK2 can be observed by using different PEV reporter genes and any effects can be confirmed.

\section{Method:}

\section{Stubble variegation assay:}

The $T(2 ; 3) S b^{v}$ is a reciprocal translocation between the second and third chromosome, placing the dominant Stubble (Sb) mutation close to second chromosome centric heterochromatin (Bishop, 1992; Hayashi et al., 1990; Weiler and Chatterjee, 2009). Since the Stubble allele is dominant, resulting in a shortening and thickening of the large bristles on the fly's body, silencing of Stubble results in a wild type bristle. Genetic crosses were performed at $25^{\circ} \mathrm{C}$ between the $\operatorname{In}(1) y^{3 P} ; T(2 ; 3) S b^{v} / T M 1$, Ubx females and the males heterozygous for CK2 alleles - Tik/TM6B, Tb or $T_{i k}^{R} / T M 6 B, T b$. The Tik/T(2;3)Sb $b^{v}$ or $T i k^{R} /$ $T(2 ; 3) S b^{v}$ progenies were identified as non-Tubby, non-Ultrabithorax. Four bristles - the anterior and posterior scutellars, were scored for longer or shorter bristle phenotypes. As internal controls we scored the bristles for $T(2 ; 3) S b^{v} / T M 6 B, T b$ flies from each of the $F 1$ generations of the earlier mentioned crosses. These 'controls' were identified as Tubby, non-Ultabithorax. Because short bristles are caused by the active expression of the $S b^{V}$ gene, increased frequencies of shorter bristles compared to that of the controls will indicate suppression, whereas, the increased frequencies of the longer bristles will be prominent features of the enhancement of silencing. 
We photographed each of the F1 flies from the crosses and sorted them according to the genotypes and phenotypes. All the flies were photographed using the same $10 \mathrm{X}$ magnification and the bristle lengthens were measured using these photographs. Every anterior and posterior scutellar bristles for each of the flies were then measured manually. Bristles less than two $\mathrm{cm}$ were counted to be Stubble, the bristles measuring more than five $\mathrm{cm}$ scored as non-Stubble and the bristles three-five $\mathrm{cm}$ were categorized as indeterminate. The data were collected and presented in Tables 2.

\section{Results and Discussions:}

The puzzling results with Tik and $T i k^{R}$, where Tik appeared to be strongly enhancing variegation while $T i k^{R}$ appeared to be strongly suppressing it prompted us to examine the effect of these two alleles of $C K 2$ on another variegating mutant, $T(2 ; 3) S b^{v}$. As described earlier, Stubble is a third chromosome dominant allele, which in $T(2 ; 3) S b^{v}$ is translocated to be adjacent to or within the centric second chromosomal heterochromatin (Bishop, 1992; Hayashi et al., 1990). Suppression of this Stubble gene expression thus produces wild type bristle phenotype; where as the proper expression is indicated by shorter bristles. We expect to get enhanced PEV effect of Stubble gene when crossed with Tik and the resultant flies should have wild type bristles. On the other hand, the effect of $T_{i k}{ }^{R}$ will either support the findings, obtained by using $w^{m 4}$, that $T i k^{R}$ is a general suppressor of variegation or will indicate that the $\mathrm{Tik}^{R}$ chromosome is altering the white's genes expression in a gene specific fashion. The doubly heterozygous flies, $T(2 ; 3) S b^{v} / T i k$, have wild type scutellar bristles (Figure: 27), which are typically more than double the length of the normal Stubble bristles. This again makes Tik an enhancer of PEV, not only in $w^{m 4}$ variegation but also in 
Stubble variegation as well. The $T(2 ; 3) S b^{v} / T i k^{R}$ flies, however, showed no effect on the variegating $S b^{v}$ allele.

The results of $T i k^{R}$ with $T(2 ; 3) S b^{V}$ do not support the earlier observations of $T i k^{R}$ s effects on $w^{m 4}$. Tik ${ }^{R}$ causes an increase in the expression of the white gene in $w^{m 4}$ yet has no effect on $T(2 ; 3) S b^{V}$, suggesting that $T i K^{R}$ is not a general suppressor of variegation. Instead, the $\mathrm{Tik}^{R}$ chromosome's effects appear to be specific to the white gene itself. It may be that a $50 \%$ reduction in CK2 activity may somehow be increasing the activity of the white gene product while a $50 \%$ reduction in CK2 activity is not sufficient to alter chromatin formation. In contrast, the lowered activity of CK2 in the Tik allele may be strongly affecting chromatin compaction to the point that it overcomes any effects on the activity of the white gene that is independent of variegation. Another alternative is that the $\mathrm{Tik}^{R}$ chromosome has acquired a second-site mutation that is increasing the expression of the white gene or the activity of the White protein and the results are independent of CK2 activity. Future experiments will be required to determine precisely why the $T i k^{R}$ chromosome increases the deposition of red eye pigment in the $w^{m 4}$ crosses. 


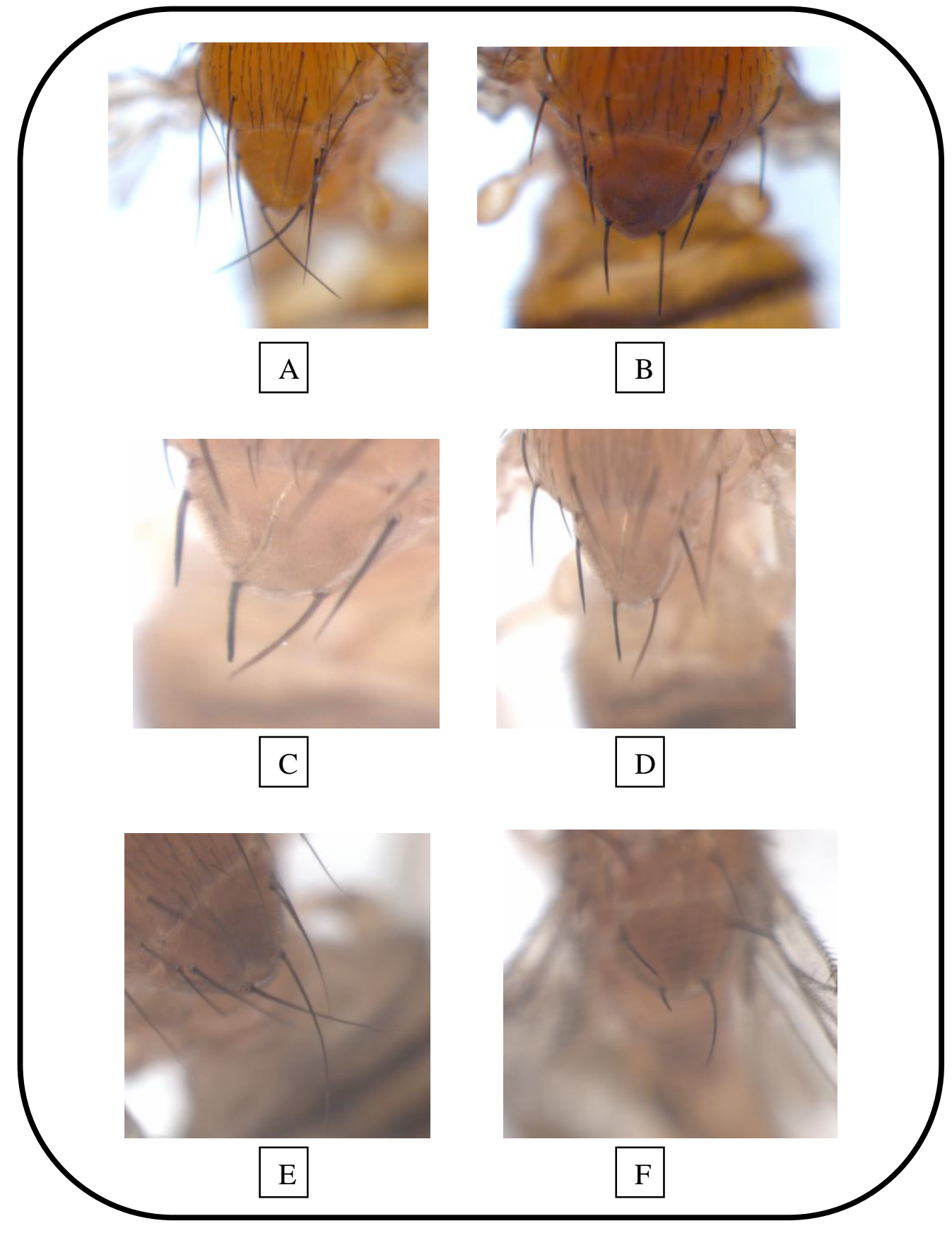

Figure 27 Effects of Tik and $T i k^{R}$ on $T(2 ; 3) S b^{V}$

A. Wild type bristles in $w^{1118}$ flies, B. Stubble bristles in h10Ga/4/TM3, Sb, C. and D. Internal controls from the $T i k$ and $T i k^{R}$ crosses with the $T(2 ; 3) S b^{v} / T M 6 B, T b$ genotypes, E. Bristles of Tik $T(2 ; 3) S b^{v}$ - note enhancement in Stubble bristles close to normal, F. Bristles of $T i k^{R} / T(2 ; 3) S b^{v}$. 
Table 2 Effect of CK2 mutant alleles on Stubble variegation by showing average number of bristles

\begin{tabular}{|c|c|c|c|c|}
\hline From & Genotypes & $\begin{array}{l}\text { Avg no. of } \\
\text { bristles }\end{array}$ & $+/-$ Std Dev & $p$-value \\
\hline \multirow{3}{*}{$\begin{array}{c}T i k / T(2 ; 3) S b^{v} \\
(n=53)\end{array}$} & $S b^{+}$ & 2.54 & 0.01 & 0.001 \\
\hline & $s b$ & 0.785 & 0.02 & 0.94 (not) \\
\hline & Indeterminate & 0.655 & 0.01 & 0.001 \\
\hline \multirow{3}{*}{$\begin{array}{c}T(2 ; 3) S b^{v} / T M 6 B, T b \\
\text { (from Tik) } \\
(n=47)\end{array}$} & $S b^{+}$ & 0.61 & 0.06 & \\
\hline & $S b$ & 0.775 & 0.18 & \\
\hline & Indeterminate & 2.605 & 0.12 & \\
\hline \multirow{3}{*}{$\begin{array}{c}T i k^{R} / T(2 ; 3) S b^{v} \\
(n=42)\end{array}$} & $\mathrm{Sb}^{+}$ & 0.94 & 0.27 & 0.512 (not) \\
\hline & $S b$ & 0.48 & 0.24 & 0.73 (not) \\
\hline & Indeterminate & 2.57 & 0.04 & 0.069 (not) \\
\hline \multirow{3}{*}{$\begin{array}{c}T(2 ; 3) S b^{v} / T M 6 B, T b \\
\text { (from TikR) } \\
(n=62)\end{array}$} & $S b^{+}$ & 0.685 & 0.02 & \\
\hline & $S b$ & 0.55 & 0.07 & \\
\hline & Indeterminate & 2.75 & 0.06 & \\
\hline
\end{tabular}




\section{Overall Conclusions:}

The results we obtained with the $S b^{V}$ allele have clarified the role of CK2 in PEV. The data obtained with Tik confirmed our observations with the $w^{m 4}$ variegating mutant, that Tik is strongly enhancing gene inactivation via heterochromatin formation. The results with $T i k^{R}$, however, did not support the observations with $w^{m 4}$. Tik ${ }^{R}$ did not act like a strong suppressor but instead appeared to have no effect on PEV, neither suppressing nor enhancing. This result is consistent with that observed with the CK2 allele CK2MB in the case of $w^{m 4}$. The easiest way to reconcile our observations is that a $50 \%$ reduction of CK2 activity is affecting some aspect of the eye pigmentation production, resulting in greater amounts of eye pigment being produced. Thus the effects observed with $T_{i k}^{R}$ are due to that biochemical pathway, and not PEV itself. In the case of Tik, the greater loss of CK2 activity (and possibly greater PP2A activity), (Kunttas-Tatli et al., 2009) does appear to favor the formation of heterochromatin. This PEV effect is sufficiently strong enough to override any effects on the pigmentation biochemical pathway. This result is also consistent with what was observed with the PP2A mutant $m$ ts. The reduction in PP2A activity acted as a moderately strong suppressor of PEV, the opposite of what was observed with the CK2-Tik allele. We can conclude, therefore, that CK2 activity is required for either the establishment, maintenance, or perpetuation of euchromatin or, conversely, that CK2 activity is required for the breakdown or otherwise negatively controls the formation of heterochromatin. PP2A would be acting in the opposite fashion, either favoring the formation of heterochromatin or inhibiting euchromatin. 


\section{Article III.}

\section{Citations:}

Ahmed, K. and Golic, K. G. (1996). Somatic reversion of chromosomal position effects in Drosophila melanogaster Genetics 144, 657-670.

Allada, R. and Meissner, R. A. (2005). Casein kinase 2, circadian clocks, and the flight from mutagenic light. Mol Cell Biochem 274, 141-9.

Allende, J. E. and Allende, C. C. (1995). Protein kinase CK2: an enzyme with multiple substrates and a puzzling regulation. FASEB J 9, 313-322.

Allis, C. D., Jenuwein, T. and Reinberg, D. (2007). Epigenetics. Cold Spring Harbour Laboratory Press, New York.

Bajpai, R., Makhijani, K., Rao, P. R. and Shashidhara, L. S. (2004). Drosophila Twins regulates Armadillo levels in response to $\mathrm{Wg} / \mathrm{Wnt}$ signal. Development 131, 1007-1016.

Barnett, B. M. and Munoz, E. R. (1998). Genetic damage induced by methylglyoxal and methylglyoxal plus X-rays in Drosophila melanogaster germinal cells. Mutation Research 421, 37 43.

Battistutta, R., Sarno, S., De Moliner, E., Papinutto, E., Zanotti, G. and Pinna, L. A. (2000). The Replacement of ATP by the Competitive Inhibitor Emodin Induces Conformational Modifications in the Catalytic Site of Protein Kinase CK2. J Biol Chem 275, 29618-29622.

Bielinski, V. A. and Mumby, M. C. (2007). Functional analysis of the PP2A subfamily of protein phosphatases in regulating Drosophila S6 kinase. Exp Cell Res.

Bischof, J., Maeda, R. K., Hediger, M., Karch, F. and Basler, K. (2007). An optimized transgenesis system for Drosophila using germ-line-specific Phi-C31 integrases. PNAS 104, 33123317.

Bishop, C. P. (1992). Evidence for intrinsic differences in the formation of chromatin domains in Drosophila melanogaster. Genetics 132, 1063-1069.

Boneta, C., Fernándezb, I., Arana, X., Bernuésa, J., Giraltc, E. and Azorín, F. (2005).

The GAGA Protein of Drosophila is Phosphorylated by CK2 Journal of Molecular Biology 351, 562572.

Bosc, D. G., Slominski, E., Sichler, C. and Litchfield, D. W. (1995). Phosphorylation of casein kinase II by p34 cdc2. J Biol Chem 270, 25872-25878.

Bose, A., Kahali, B., Zhang, S., Lin, J.-M., Allada, R., Karandikar, U. and Bidwai, A. (2006). Drosophila CK2 regulates lateral-inhibition during eye and bristle development. Mech Dev 123, 649664.

Chantalat, L., Leroy, D., Filhol, O., Nueda, A., Benitez, M. J., Chambaz, E. M., Cochet, C. and Dideberg, O. (1999). Crystal structure of the human protein kinase CK2 regulatory subunit reveals its zinc finger-mediated dimerization. EMBO J 18, 2930-2940.

Cohen, G. B., Ren, R. and Baltimore, D. (1995). Modular binding domains in signal transducing proteins. Cell 80, 237-248.

Cooper, G. M. and Hausman, R. E. (1959). Cell: A Molecular Approach: Sinauer Associates.

Dominguez, I., Mizuno, J., Wu, H., Song, D. H., Symes, K. and Seldin, D. C. (2004). Protein kinase CK2 is required for dorsal axis formation in Xenopus embryos. Dev Biol 274, 110-24. 
Dotan, I., Ziv, E., Dafni, N., Beckman, J. S., McCann, R. O., Glover, C. V. and Canaani, D. (2001). Functional conservation between the human, nematode, and yeast CK2 cell cycle genes. Biochem Biophys Res Commun 288, 603-9.

Downs, J. A., Nussenzweig, M. C. and Nussenzweig, A. (2007). Chromatin dynamics and the preservation of genetic information. Nature 447, 951-958.

Eissenberg, J. C. and Elgin, S., C. R. (2000). The HP1 protein family: getting a grip on chromatin. Current Opinion on Genetics and Development 10, 204-210.

Ephrussi, B. and Herold, J. L. (1943). Studies of eye pigments of Drosophila Genetics 29, 148 175.

Felsenfeld, G. and Groudin, M. (2003). Controlling the double helix. Nature 421.

Ford, H. L., Landesman-Bollag, E., Dacwag, C. S., Stukenberg, P. T., Pardee, A. B. and Seldin, D. C. (2000). Cell Cycle-regulated Phosphorylation of the Human SIX1 Homeodomain Protein. J Biol Chem 275, 22245-22254.

Girton, J. R. and Johansen, K. M. (2008). Chromatin Structure and the Regulation of Gene expression: The lessons of PEV in Drosophila. Advances in Genetics 61.

Graham, K. C. and Litchfield, D. W. (2000). The regulatory beta subunit of protein kinase CK2 mediates formation of tetrameric CK2 complexes. J Biol Chem 275, 5003-5010.

Greil, F., Wit, W. d., Bussemaker, H. J. and Steensel, B. v. (2007). HP1 controls genomic targeting of four novel heterochromatin proteins in Drosophila EMBO J. 26, 741-751.

Groth, A. C., Fish, M., Nusse, R. and Calos, M. P. (2003). Construction of Transgenic Drosophila by using the Site-Specific integrase from phage Phi-C31. Genetics 166, 1775-1782.

Guerra, B., Boldyreff, B., Sarno, S., Cesaro, L., Issinger, O. G. and Pinna, L. A. (1999). CK2: a protein kinase in need of control. Pharmacol Ther 82, 303-313.

Gurudatta, B. V. S., L. S.; Parnaik, V. K. (2010). Lamin C and chromatin organization in Drosophila. Journal of Genetics 89, 37-49.

Hayashi, S., Ruddell, A., Sinclair, D. and Grigliatti, T. (1990). Chromosomal structure is altered by mutations that suppress or enhance position effect variegatiion. Chromosoma 99, 391-400.

Henikoff, S. (1990). Position effect variegation after 60 years. Trends Genetics 6, 422-426.

Hunter, T. and Cooper, J. A. (1986). Viral oncogenes and tyrosine phosphorylation. 191-246.

Janssens, V. and Goris, J. (2001). Protein phosphatase 2A: a highly regulated family of serine/threonine phosphatases implicated in cell growth and signalling. Biochem J 353, 417-39.

Junttila, M. R., Li, S. P. and Westermarck, J. (2008). Phosphatase-mediated crosstalk between MAPK signaling pathways in the regulation of cell survival. FASEB $J$ 22, 954-65.

Karpen, G. H. (1994). Posiion effect variegation and the new biology of heterochromatin. Current Opinion on Genetics and Development 4, 281-291.

Keller, D. M., Zeng, X., Wang, Y., Zhang, Q. H., Kapoor, M., Shu, H., Goodman, R., Lozano, G. and Zhao, Y. H. (2001). A DNA damage-induced p53 serine 392 kinase complex contains CK2, hSpt16, and SSRP1. Mol Cell 7, 283-292.

Kelliher, M. A., Seldin, D. C. and Leder, P. (1996). Tal-1 induces T cell acute lymphoblastic leukemia accelerated by casein kinase II alpha. EMBO J 15, 5160-5166.

Kunttas-Tatli, E., Bose, A., Kahali, B., Bishop, C. P. and Bidwai, A. P. (2009). Functional dissection of Timekeeper (Tik) implicates opposite roles for CK2 and PP2A during Drosophila neurogenesis. Genesis 47, 647-658.

Lee, D., Redfern, O. and Orengo, C. (2007). Predicting protein function from sequence and structure. Nat Rev Mol Cell Biol 8, 995-1005. 
Lin, J. M., Kilman, V. L., Keegan, K., Paddock, B., Emery-Le, M., Rosbash, M. and Allada, R. (2002). A role for casein kinase 2alpha in the Drosophila circadian clock. Nature 420, 816-820.

Lyon, M. F. (1961). Gene action in the X-chromosome of thec Mouse (Mus musculus L.). Nature (abstract) 190, 372-373.

Manning, L. and Doe, C. (1999). Prospero distinguishes sibling cell fate without asymmetric localization in the Drosophila adult external sense organ lineage. Develop 126, 2063-2071.

Maridor, G., Park, W., Krek, W. and Nigg, E. A. (1991). Casein Kinase II. cDNA sequences, developmental expression, and tissue distribution of mRNAs for alpha, alpha' and beta subunits of the chicken enzyme. J Biol Chem 266, 2362-2368.

Mayer-Jaekel, R. E., Baumgartner, S., Bilbe, G., Ohkura, H., Glover, D. M. and Hemmings, B. A. (1992). Molecular cloning and developmental expression of the catalytic and 65-kDa regulatory subunits of protein phosphatase 2A in Drosophila. Mol Biol Cell 3, 287-98.

Meggio, F. and Pinna, L. A. (2003). One-thousand-and-one substrates of protein kinase CK2. FASEB J 17, 349-368.

Messenger, M. M., Saulnier, R. B. (2002). Interaction between protein kinase CK2 and pin1. J. Biol Chem 277, 23054-23064.

Moliner, E. D., Moro, S., Sarno, S., Zagotto, G., Zanotti, G., Pinna, L. A. and Battistutta, R. (2003). Inhibition of protein kinase CK2 by anthraquinone-related compounds. J Biol Chem 278, 1831-1836.

Moorhead, G. B. G., Trinkle-Mulcahy, L. and Ulke-Lemee, A. (2007). Emerging roles of nuclear protein phosphatases. Nature 8, 234-244.

Mumby, M. (2007). The 3D structure of protein phosphatase 2A: new insights into a ubiquitous regulator of cell signaling. ACS Chem Biol 2, 99-103.

Niefind, K., Guerra, B., Ermakowa, I. and Issinger, O. G. (2001). Crystal structure of human protein kinase CK2: insights into basic properties of the CK2 holoenzyme. EMBO J 20, 5320-5331.

Niefind, K., Guerra, B., Pinna, L. A., Issinger, O. G. and Schomburg, D. (1998). Crystal structure of the catalytic subunit of protein kinase CK2 from Zea mays at 2.1 A resolution. EMBO J 17, 24512462.

Padmanabha, R., Chen-Wu, J. L. P., Hanna, D. E. and Glover, C. V. C. (1990). Isolation, sequencing, and disruption of the yeast $C K A 2$ gene: casein kinase II is essential for viability in Saccharomyces cerevisiae. Mol Cell Biol 10, 4089-4099.

Pawson, T. and Nash, P. (2000). Protein-protein interactions define specificity in signal transduction. Genes \& Dev 14, 1027-1047.

Pinna, L. A. (1990). Casein kinase 2: an 'eminence grise' in cellular regulation? Biochim Biophys Acta 1054, 267-284.

Rasmussen, T., Skjøth, I. H. E., Jensen, H. H., Niefind, K., Boldyreff, B. and Issinger, O. G. (2005). Biochemical characterization of the recombinant human Drosophila homologues Timekeeper and Andante involved in the Drosophila circadian oscillator. Mol Cell Biochem 274, 151-161.

Reuter, G. and Spierer, P. (1992). Position effect variegation and chomatin proteins. BioEssays 14, 605-611.

Richards, E. J. and Elgin, S., C. R. (2002). Epigenetic codes for heterochromatin formation and silencing: Rounding up the usual suspects. Cell 108, 489-500.

Sage, B. T. and Csink, A. K. (2003). Heterochromatic self-association, a determinant of nuclear organization, does not require sequence homology in Drosophila. Genetics 165, 1183-1193.

Sandell, L. L. and Zakian, V. A. (1992). Trends Cell Biol. 2. 
Sayed, M., Kim, S. O., Salh, B. S., Issinger, O. G. and Pelech, S. L. (2000). Stress-induced activation of protein kinase CK2 by direct interaction with p38 mitogen-activated protein kinase. $J$ Biol Chem 275, 16569-73.

Schotta, G., Ebert, A., Dorn, R. and Reuter, G. (2003). Position effect variegation and the genetic dissection of chromatin regulation in Drosophila. semin Cell Dev Biol. 14, 67-75.

Song, D. H., Sussman, D. J. and Seldin, D. C. (2000). Endogenous protein kinase CK2 participates in Wnt signaling in mammary epithelial cells. J Biol Chem 275, 23790-23797.

Spofford, J. B. (1976). Position effect variegation in Drosophila. Genetics and Biology of Drosophila 1C, 955-1018.

Steller, H. and Pirrotta, V. (1985). Expression of the Drosophila white gene under the control of the Hsp-70 heat shock promoter. EMBO J. 4, 3765-3772.

Surani, M. A., Hayashi, K. and Hajkova, P. (2007). Genetic and Epigenetic Regulators of Pluripotency. Cell 128, 747-762.

Talbert, P. B. and Henikoff, S. (2000). A reexamination of spreading of position-effect variegation in the white-roughest region of Drosophila melanogaster. Genetics 154, 259-272.

Tartof, K. D., Bishop, C., Jones, M., Hobbs, A. and Locke, J. (1989). Towards an understanding of position effect variegation. Dev. Genetics 10, 162-176.

Tartof, K. D., Jones, M. and Hobbs, C. (1984). A sructural basis for variegting position effects. Cell 37, 869-878.

Tawfic, S. and Ahmed, K. (1994). Association of casein kinase 2 with nuclear matrix. Possible role in nuclear matrix protein phosphorylation. J Biol Chem 269, 7489-7493.

Torres, J. and Pulido, R. (2001). The tumor suppressor PTEN is phosphorylated by the protein kinase CK2 at its C-terminus. J Biol Chem 276, 993-998.

Tremethick, D. J. (2007). Higher-Order Structures Of Chromatin: The Elusive 30 nm Fibre. Cell 128, 651-654.

Tuazon, P. T. (1991). Caesine Kinase I and II - structure, function and regulation. 23.

Turner, B. M. (2007). Defining the epigenetic code. Nature Cell Biology 9, 2-6.

Ussery, D. (1998). Introduktion til Bioinformatik. Tirsdag 17.

Venken, K. J., Carlson, J. W., Schulze, K. L., Pan, H., He, Y., Spokony, R., Wan, K. H., Koriabine, M., deJong, P. J., White, K. et al. (2009). Versatile P[acman] BAC libraries for transgenesis studies in Drosophila melanogaster. Nat Methods 6, 431-434.

Vereshchagina, N., Ramel, M. C., Bitoun, E. and Wilson, C. (2008). The protein phosphatase PP2A-B' subunit Widerborst is a negative regulator of cytoplasmic activated Akt and lipid metabolism in Drosophila. J Cell Sci 121, 3383-92.

Virshup, D. M. and Shenolikar, S. (2009). From promiscuity to precision: protein phosphatases get a makeover. Mol Cell 33, 537-45.

Waldren, C., Correll, L., Sognier, M. and Puck, T. (1986). Measurement of low level of x-ray mutagenesis in relation to human disease. Genetics 83, 4839-4843.

Wallrath, L. L. and Elgin, S. C. R. (1995). Position effect variegation is associated with an altered chromatin structure. Genes Dev. 9, 1263-1277.

Wassarman, D. A., Solomon, N. M., Chang, H. C., Karim, F. D., Therrien, M. and Rubin, G. M. (1996). Protein phosphatase 2A positively and negatively regulates Ras1-mediated photoreceptor development in Drosophila. Genes \& Dev 10, 272-8.

Weiler, K. S. and Chatterjee, S. (2009). The Multi-AT-Hook chromosomal protein of Drosophila melanogaster, D1, is dispensable for viability. Genetics 182, 145-159. 
Weiler, K. S. and Wakimoto, B. T. (1995). Heterochromatin and gene expression in Drosophila. Annual Review Genetics 29, 577-605.

Xing, Y., Xu, Y., Chen, Y., Jeffrey, P. D., Chao, Y., Lin, Z., Li, Z., Strack, S., Stock, J. B. and Shi, Y. (2006). Structure of protein phosphatase 2A core enzyme bound to tumor-inducing toxins. Cell 127, 341-53.

Xu, Y., Xing, Y., Chen, Y., Chao, Y., Lin, Z., Fan, E., Yu, J. W., Strack, S., Jeffrey, P. D. and Shi, Y. (2006). Structure of the protein phosphatase 2A holoenzyme. Cell 127, 1239-51.

Yikang, S. R. and Golic, K. G. (1998). Dominant Defects in Drosophila Eye Pigmentation Resulting

From a

Euchromatin-Heterochromatin Fusion Gene. Genetics 150, 1551 - 1566.

Zhao, T. and Eissenberg, J. C. (1999). Phosphorylation of heterochromatin protein 1 by casein kinase II is required for efficient heterochromatin binding in Drosophila. J Biol Chem 274, 15095.

Zhao, T., Heyduk, T. and Eissenberg, J. C. (2001a). Phosphorylation site mutation in heterochromatin Protein 1 (HP1) reduce or eliminate silencing activity. The Journal of Biologocal Chemistry 276, 9512-9518.

Zhao, T., Heyduk, T. and Eissenberg, J. C. (2001b). Phosphorylation site mutations in Heterochromatin Protein1 (HP1) reduce or eliminate silencing activity. The Journal of Biologocal Chemistry 276, 9512-9518. 


\section{Article IV.}

\section{Appendix}

Construction of a tool to measure the effect of Position Effect Variegation (PEV) in vivo 


\section{Introduction:}

Several studies on PEV have revealed that there are a large number of genetic and environmental modifiers which affect the variegating phenotypes. There are not only the genetic $\mathrm{Su}(\mathrm{var}) \mathrm{S}$ or $\mathrm{E}$ (var)s modifiers that modulate PEV, but also temperature, diet, and possibly other environmental factors play a role in modifying the phenotypic effects. It has been shown that low temperatures $\left(16-18^{\circ} \mathrm{C}\right)$ induce the enhancement of euchromatic gene silencing resulting in more intense mutant phenotypes. On the contrary, the higher temperature $\left(29^{\circ} \mathrm{C}\right)$, the more euchromatin prevails (Girton and Johansen, 2008) thus reducing the severity of the mutant phenotype. PEV effect can also be affected by the relative amount of heterochromatin present (Spofford, 1976). It is believed that extra heterochromatin acts as a sink to absorb the components of heterochromatin, reducing the amount of gene silencing in PEV. We must also ensure that any treatments are due to the dynamics between euchromatin versus heterochromatin and not due to the treatment effecting the normal expression of the reporter gene itself. Thus it becomes essential to construct a genetic tool to manipulate the PEV effects in a fully controlled manner. To ensure this we have generated transgenic lines with reporter genes white + CFP or white + YFP using site-specific insertion (Bischof et al., 2007; Groth et al., 2003; Venken et al., 2009). These lines will further be used to isolate mutants variegating for white and either CFP or YFP. Transheterozygotes, for instance white $+C F P^{V} /$ white $+Y F P$, will allow examination of the effects of different factors on PEV using the non-variegating reporter (in the instance above, YFP) as an ideal internal control to eliminate those factors not involved in the dynamic interactions between heterochromatin and euchromatin. Factors affecting 
both $C F P^{V}$ and YFP may be general transcription and/or translational factors and can be eliminated as factors affecting PEV analyzed to examine the effects of various agents on PEV.

\section{Method:}

(a) Generating the tool for measuring PEV:

(i) Making the construct pUASTattB-CFP and pUASTattB-YFP:

The vector $p U A S T$-attB was obtained from Bischof's lab. The $p U A S T$-attB plasmid contains

a 285-bp attB fragment, the white ${ }^{+}$selectable marker, a UAS-MCS-SV40 cassette and a single loxP site. The vectors $p E T 30 a-Y F P$ and $p E T 30 a-C F P$ were previously constructed in the Bidwai and Bishop laboratories. CFP and YFP were cut out of the pET30a vector using BamH1 and Not1 restriction enzymes and ligated into the Bglll-Notl digested pUAST-attB vector separately. The newly constructed vectors ( $p U A S T$-attB-CFP and $p U A S T$-attB-YFP) were confirmed by various other double restriction digestions [EcoR1-BamH1 and EcoR1Not1) and also were sequenced.

\section{(ii) Injecting into the fly genome:}

The construct $p U A S T$-attB-CFP and $p U A S T$-attB-YFP DNA were sent to the BestGene Inc. for the proper insertion into specific positions of the fly genome. The method chosen is known as 'site specific insertion by using phi C31 integrase' (Bischof et al., 2007). The landing genomic sites have been generated by specific landing constructs composed of 221-bp of an attP docking site and a DsRFP marker gene, driven by the $3 x P 3$ promoter, attached to the tubulin- $\alpha 1$ 3' UTR element. The marker cassette is flanked by loxP sites; 
whereas the whole landing site construct is bounded by mariner inverted repeats. Two fly strains containing the 'attP' landing sites at two different locations in the fly genome, were selected for this particular study. One strain (Bloomington stock \# 24480) has the 'attP' landing site at the $2 \mathrm{~A}$ location of the X-chromosome, whereas the other strain (Bloomington stock \# 24483) has the second chromosomal 'attP' landing site at the cytological location of 2R 51D. The site-specific insertions are to be done via the endogenous integrase sources at the cytological locations of $102 \mathrm{D}$ and $2 \mathrm{~A}$ for the second and $\mathrm{X}$ chromosomal locations respectively. The $\varnothing \mathrm{c} 31$ integrase mediates recombination between attB (in the transgene) and attP (in the fly genome) sites, resulting in the integration of the construct $p U A S T$-attBCFP or $p U A S T$-attB-YFP into the respective landing sites, thereby creating the two hybrid sites attL (att Left) and attR (att Right). After the injection, the proper identification of the transformants was conducted and processed to eliminate the integrase. The fly stocks with the proper insertions were then sent back from the company and maintained by the Bishop laboratory. The X-chromosome inserted fly strains are referred to as 'X-chromosome pUAST-attB-CFP and the second chromosome stock are referred to as second chromosome $p U A S T$-attB-CFP. 


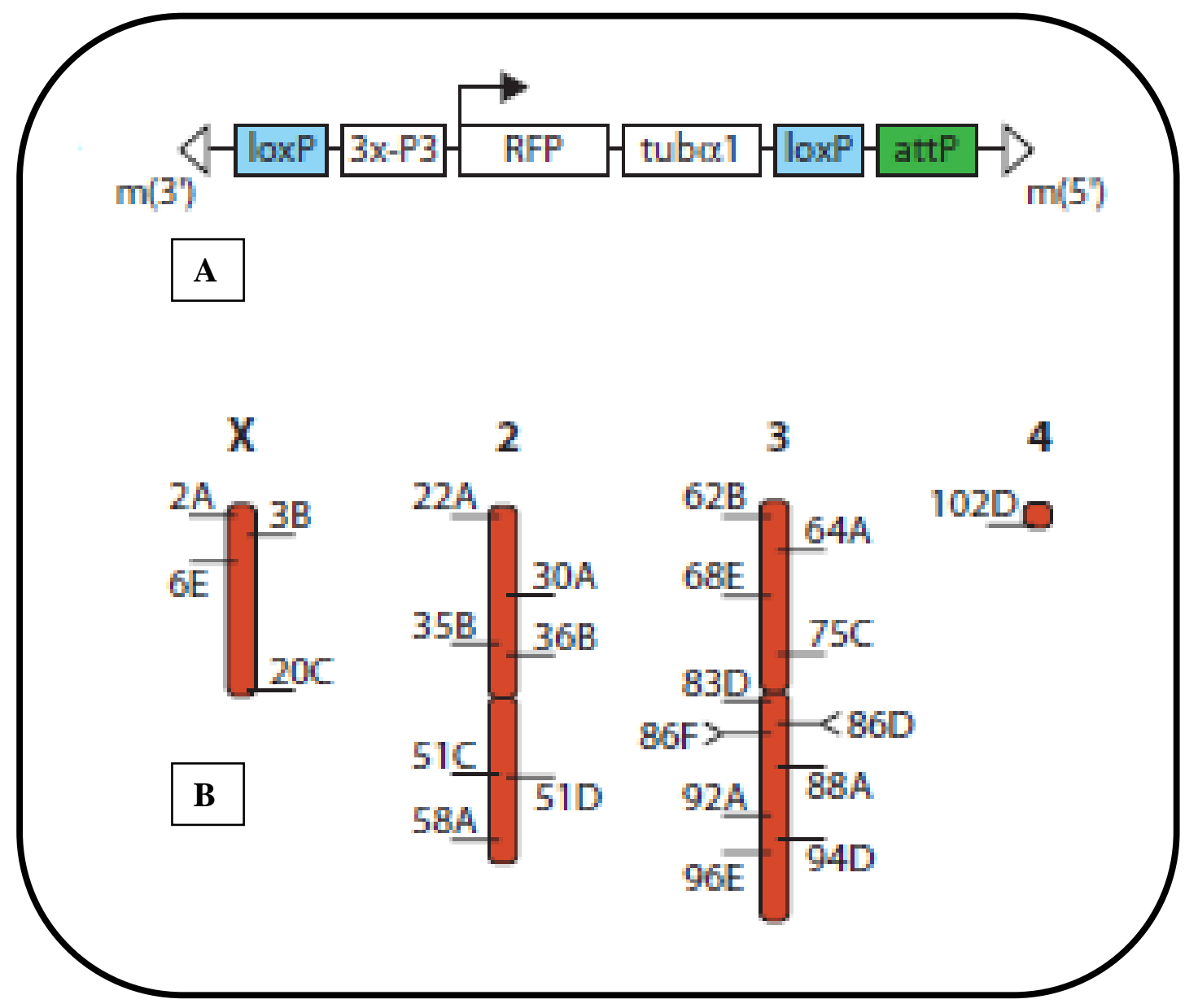

Figure 28 Design of construct and landing sites

A. Design of landing site construct with $221 \mathrm{bp}$ attP site, $3 \times P 3$ promoter driven DsRFP marker gene attached to the tubulin-a1 3'UTR element. The marker cassette is flanked by loxP sites. The landing site construct is bounded by mariner inverted repeats (inverted repeats are shown in open triangles). B. The four major Drosophila chromosomes showing the cytological positions with the 25 different $Z H$-attP intergenic landing sites. In this study we used 2A-X and 51D-2R [Depicted from: (Bischof et al., 2007)]. 
Table 3: The list of strains used in the study for constructing transgenic lines

\begin{tabular}{|c|c|c|c|c|}
\hline BSC stock \# & Name & Genotype & $\begin{array}{c}\text { Estimated } \\
\text { cytological site }\end{array}$ & Chromosome \\
\hline 24480 & ФIV-2A & $\begin{array}{c}y \text { whas } Z H- \\
2 A ;+;+; \\
\text { M\{eGFP.vas- } \\
\text { int.Dm\}ZH-102D }\end{array}$ & $\overline{X 2 A}$ & Chromosome 1 \\
\hline 24483 & $\Phi X-51 D$ & $\begin{array}{c}y w \\
\text { M\{eGFP.vas- } \\
\text { int.Dm\}ZH-2A; } \\
\text { ZH-51D; +; + }\end{array}$ & 2R 51D & Chromosome 2 \\
\hline
\end{tabular}




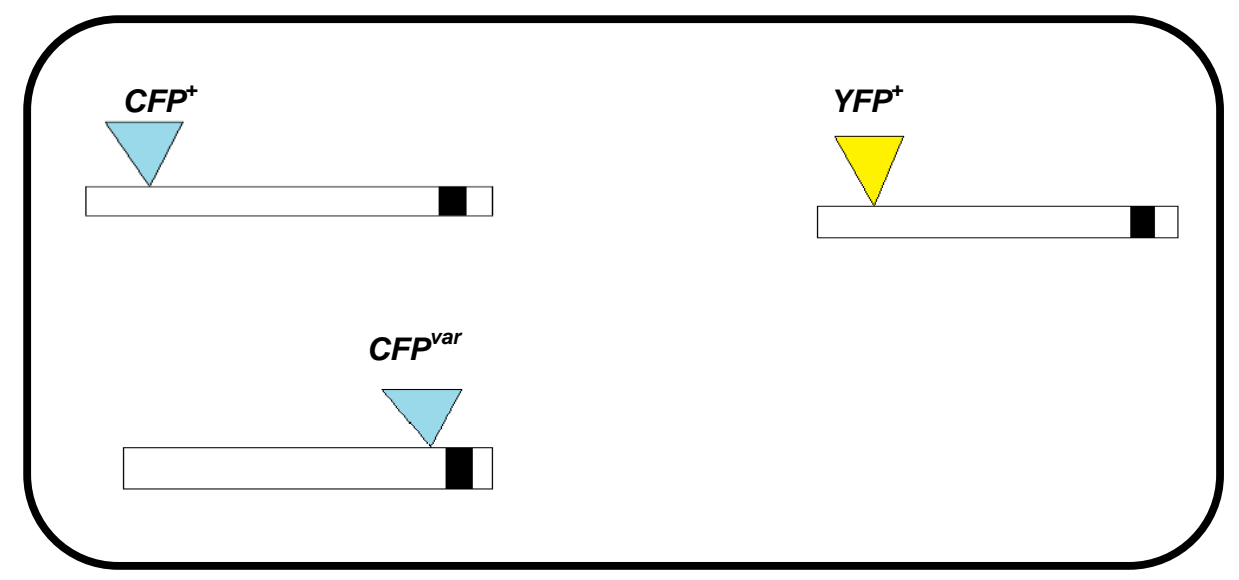

Figure 29 Cartoon of transgenic lines constructed in the study with the reporter genes locations with proximity to the heterochromatin before and after mutagenesis

One single chromosome with transgenic CFP and YFP insertions and the Xray mutagenized inversion with the CFP are shown in the figure. In this study we have generated two individual transgenic lines with CFP and YFP respectively as shown in the first line labeled as $C F P^{+}$and $Y F P^{+}$. Also in the second line there is a cartoon showing the inverted transgenic line, closer to the heterochromatic block (shaded box) after X-ray mutagenesis - labeled as CFPvar. This variegating mutant will be identified by variegation of the white transgene. 
(iii) Expanding and maintaining the transformed flies:

Both of these stocks will later be sent for gamma-ray exposure for the induction for chromosomal inversions (Barnett and Munoz, 1998; Waldren et al., 1986).

\section{(b) Fly Mutagenesis:}

The balanced second chromosome insertion line was selected for $\mathrm{y}$-ray mutagenesis. Three to five day old males were collected (30-100 males per mutagenesis) and were irradiated using the Gamma cell 1000 irradiator located at The WVU Health Sciences Center. The flies were left in $1.5 \mathrm{ml}$ eppendorf tubes (20 flies in each) and were placed inside the container to be irradiated for 7 minutes for $4000 \mathrm{rads} / \mathrm{min}$ radiation from a $137 \mathrm{Cs}$ source under ambient temperature and atmospheric conditions. After the irradiation the flies were immediately transferred to vials with food and kept at room temperature for several hours to recover from any ill effects from the mutagenesis. Single irradiated males were then crossed with two to

three female virgins per vial of the second chromosome balancer stock w; Sco/CyO and maintained at $25^{\circ} \mathrm{C}$ temperature. The parents were cleared out on the seventh or tenth day after the crosses were set up and the F1 generations from each line were observed for any variegated white phenotypes. 


\section{Results and Discussions:}

Once the CFP variegated fly is obtained, the line will be maintained by mating the fly with the opposite sex of w; Sco/CyO balancer fly to generate a stable stock. These will then be employed as variegating fly lines for next set of experiments. As already mentioned, the mutagenized variegating fly will be relatively easy to identify because of the variegation for the white gene and, due to the spreading nature of heterochromatin, we can be certain that any such mutants will also variegate for the CFP gene as well. The non-variegating YFP containing chromosome will serve as our internal control against the variegation of CFP. The PEV effect of different modifiers and CK2 alleles can then be observed by using simple F1 generation genetic crosses followed by fluorescence microscopic analysis. 